\title{
The Effect of Asymmetry on Pregnancy-Related Pain in the Postpartum Period
}

\author{
Krista G. Meder \\ West Virginia University, km0047@mix.wvu.edu
}

Follow this and additional works at: https://researchrepository.wvu.edu/etd

Part of the Biomechanics Commons, Exercise Science Commons, Physical Therapy Commons, and the Sports Sciences Commons

\section{Recommended Citation}

Meder, Krista G., "The Effect of Asymmetry on Pregnancy-Related Pain in the Postpartum Period" (2018). Graduate Theses, Dissertations, and Problem Reports. 3729.

https://researchrepository.wvu.edu/etd/3729

This Thesis is protected by copyright and/or related rights. It has been brought to you by the The Research Repository @ WVU with permission from the rights-holder(s). You are free to use this Thesis in any way that is permitted by the copyright and related rights legislation that applies to your use. For other uses you must obtain permission from the rights-holder(s) directly, unless additional rights are indicated by a Creative Commons license in the record and/ or on the work itself. This Thesis has been accepted for inclusion in WVU Graduate Theses, Dissertations, and Problem Reports collection by an authorized administrator of The Research Repository @ WVU. For more information, please contact researchrepository@mail.wvu.edu. 


\title{
THE EFFECT OF ASYMMETRY ON PREGNANCY-RELATED PAIN IN THE POSTPARTUM PERIOD
}

\author{
Krista Meder
}

Thesis submitted

to the School of Medicine at West Virginia University in partial fulfillment of the requirements for the degree of

Master of Science in Exercise Physiology

\author{
Jean McCrory, Ph.D., Chair \\ Corrie Mancinelli, PT, Ph.D. \\ Kristin Phillips, DPT. \\ Division of Exercise Physiology \\ Department of Human Performance and Applied Exercise Science
}

Morgantown, West Virginia

2018

Keywords: asymmetry, alignment, pain, postpartum, pregnancy, pelvic, low back, lower extremities

Copyright 2018 Krista Meder 


\section{ABSTRACT \\ The Effect of Asymmetry on Pregnancy-Related Pain in The Postpartum Period Krista Meder}

Nearly $50 \%$ of women experience back pain and other lower extremity pain during pregnancy, with many reporting lasting pain postpartum. Pregnant women experience changes to their pelvis and lower extremities that do not always return to pre-pregnancy baseline. Not much is known of the lingering effects of pregnancy related asymmetry and its relationship to pain. Therefore, the purpose of this study was to assess asymmetries of the pelvis and lower extremities to determine whether malalignment is related to areas of pain at the low back, hip, thigh, knee, leg, and foot/ankle. Methods: Seventeen postpartum women and seven nulliparous controls were recruited to participate. Postpartum women were placed in a 'no pain' and 'pain" group based on a Visual Analog Scale pain questionnaire. Biomechanical measurements were taken bilaterally for: leg length, foot width, foot length, arch drop, arch index, arch height index, arch rigidity index, rearfoot angle, dynamic knee valgus, and hip muscular strength.

Measurements of hypermobility and flexibility were taken using Beighton's scale and Sit and Reach test. Results/Conclusion: Several relationships exist between pelvic and lower extremity asymmetry and pain in postpartum women. We identified multiple areas of asymmetry at the hip, knee, and foot that were correlated to pain. This information may be helpful to clinicians and the treatment of asymmetries during pregnancy to prevent pain postpartum. With the high prevalence of pain that still remains postpartum, further research is necessary. A larger sample size is needed to validate the trends found in this study regarding asymmetry and pain. 


\section{ACKNOWLEDGMENTS}

I would like to thank my thesis advisor Dr. Jean McCrory. Her unwavering support and understanding have allowed me to succeed and accomplish more than I thought possible here at West Virginia University. Dr. McCrory truly inspires me daily with her dedication to her work, students, and family. Her extensive knowledge of her field has helped me obtain the skills necessary to move further in my education and career. I was sincerely blessed to have her as my mentor.

I would also like to thank Dr. Corrie Mancinelli and Dr. Kristin Phillips for their expertise and valuable input with my thesis. I am grateful for their willingness to help, and their insightful ideas.

Lastly, I would like to thank my family and friends for their endless support and encouragement over the past several years.

Krista Meder 


\section{Contents}

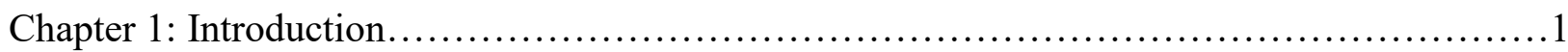

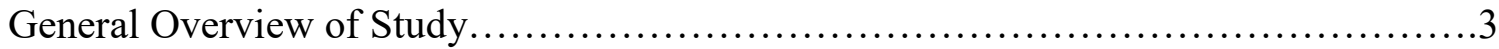

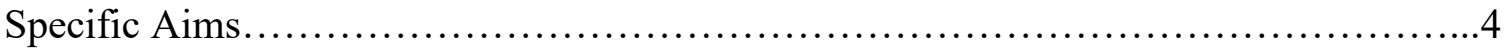

Background and Significance......................................................

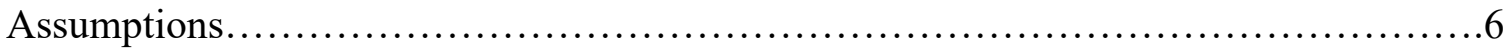

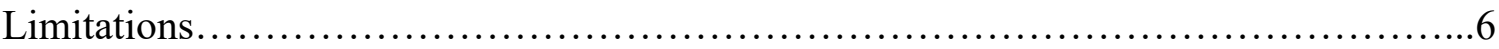

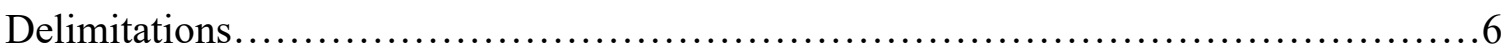

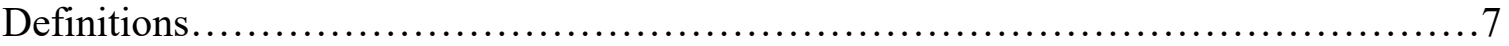

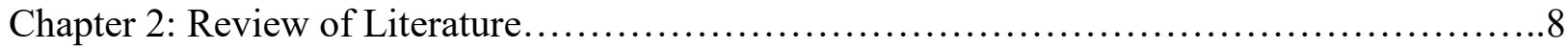

Pain During and After Pregnancy................................................. 8

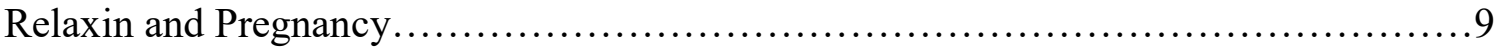

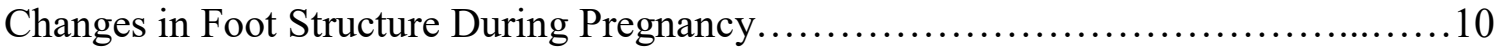

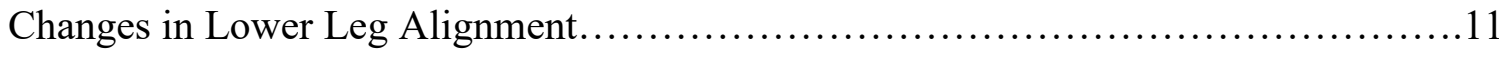

Changes in Pelvic Alignment.................................................... 11

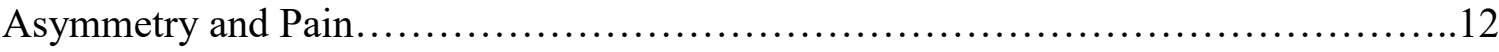

Exercise and Pregnancy............................................................ 13

Hip Strength, Leg Alignment, and Leg Pain.......................................13

Spinal Posture During Pregnancy and Postpartum..................................15

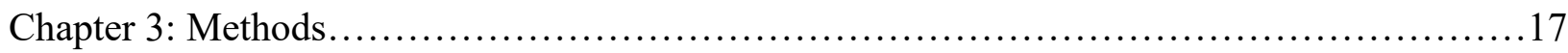

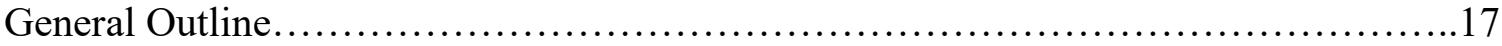

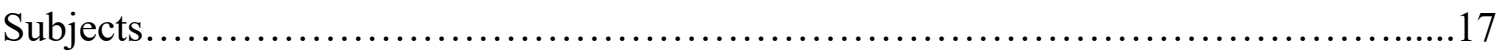

Subject Demographics.......................................................... 18

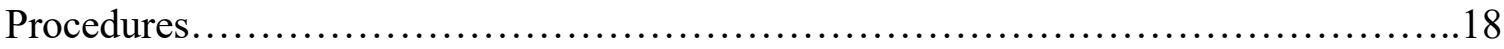

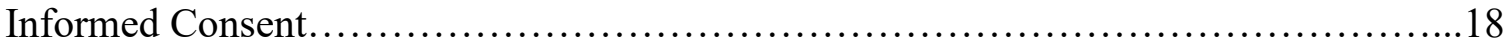

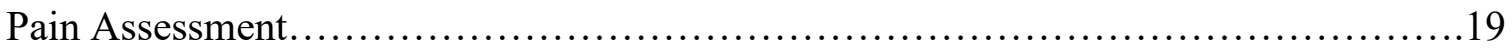

Biomechanical Assessments....................................................... 19

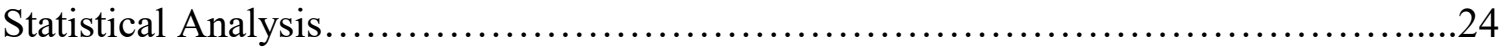


Chapter 4: Results............................................................26

Description of Postpartum Pain.............................................26

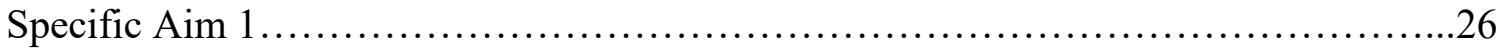

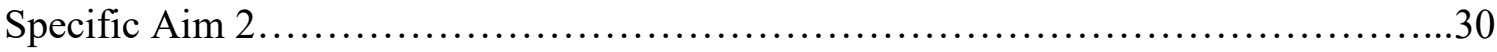

Ancillary Comparison Between Groups.......................................... 34

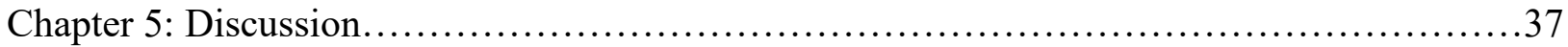

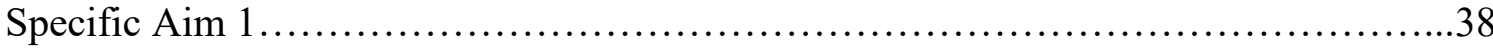

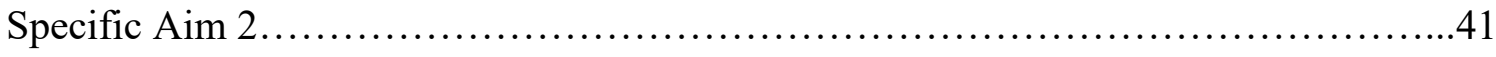

Ancillary Data............................................................. 43

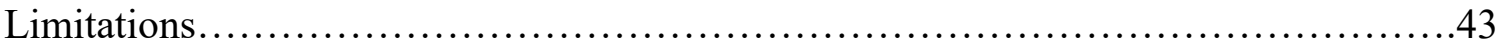

Future Research........................................................44

Conclusion.............................................................. 45

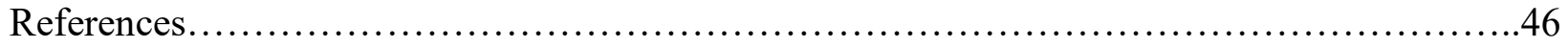

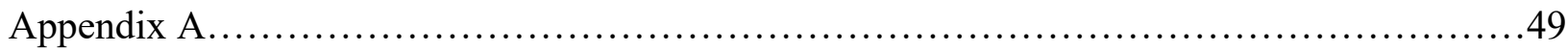

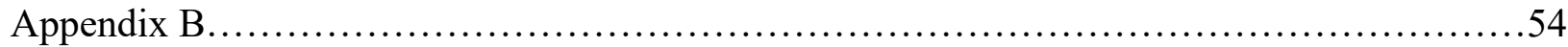

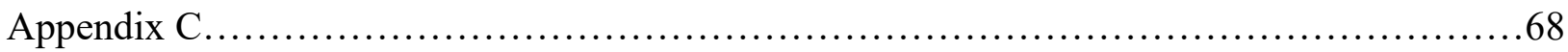

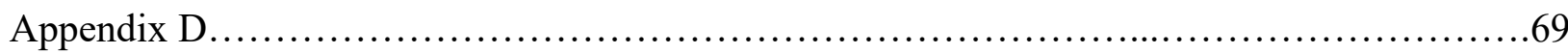




\section{Chapter 1: Introduction}

Low back and lower extremity pain occurs in nearly $50 \%$ of all women during pregnancy (1, 2). This pain is associated with anthropomorphic and physiological changes such as increase in body mass (3), anterior tilt of the pelvis $(4,5)$, and an increase in joint laxity (5). Many of these changes, especially pain, either stay the same or are slightly reduced during the postpartum period.

Nearly $40 \%$ of women who report low back pain during pregnancy also report pain postpartum (6). Of the pregnant women with the most severe pain, approximately one fourth of them report chronic pelvic pain long-term postpartum (7). Back pain during pregnancy is highly prevalent as around $50 \%$ of women report it; furthermore, one in four women experience low back pain postpartum (6). Even women who did not experience pain during pregnancy may develop back pain postpartum (6). Also, one in five pregnant women report pelvic girdle pain (7). Additionally, postpartum women experience more overall lower extremity pain than nulliparous women (8). Thus, this pain is a major concern as it may impact daily function.

The serum concentration of Relaxin has been correlated with pelvic pain, and Vullo et al. (8) suggested that hip pain may be the result of pelvic asymmetry subsidiary to hormonally induced ligamentous laxity. Relaxin is a primary contributor to increased joint laxity during pregnancy. The greatest concentration of serum Relaxin occurs in the first trimester; however, the effects are most apparent in the third trimester (5). Relaxin increases the flexibility of the ligaments, allowing for the widening of the symphysis pubis and sacroiliac joint to create a cradle to carry the fetus (9). This also allows for a wider pelvic inlet for vaginal childbirth (9). However, the effects of Relaxin are not limited to the sacro-pelvic region, as peripheral joint ligaments become 
less stiff and more compliant (10). Therefore, it is important to look at muscular flexibility as well as Relaxin's effect on the hypermobility of the joints.

Pregnancy is associated with notable alterations to foot structure, as authors have reported decreased arch height (11), increased arch drop (12), decreased arch rigidity (11), increased foot width (3), and increased foot length (3) in pregnant women compared to controls. It should be noted that it is not known if these changes are due to the hormonal changes in pregnancy or to the increased body weight seen in pregnancy, as increased body mass has also been shown to alter the foot structure in non-pregnant populations $(3,12)$.

Anthropometric changes that developed during pregnancy may persist postpartum, and thus may contribute to pain. Anecdotally, many women report increased foot length, as evidenced by a larger shoe size, following pregnancy (13). Several researchers have quantified an increased foot length, decreased arch height and arch rigidity indices, and increased arch drop in postpartum women $(5,11)$. These changes are thought to be permanent. An examination of multiparous women revealed that the greatest change of the foot mostly occurred from the first pregnancy (11).

Although several studies have examined the alignment of the lower extremities and its relationship to pain in pregnant women $(4,14,15)$, there are limited data on the relationship of the asymmetries and pain from pregnancy relating to chronic pain postpartum. A careful review yielded only one study that examined the relationship between peripheral joint laxity and postpartum back pain (16). Another study used a non-validated questionnaire to examine pain and its relationship to the postpartum period, but they did not assess alignment (8).

Hip girdle strength may also be related to low back pain after pregnancy (17). This may be a factor during pregnancy, but maximal strength testing is contraindicated because of concern for a 
dangerous increase in intra-abdominal pressure and fetal harm (18). A waddle is usually apparent in gait and may be related to weakened hip musculature (5), but this cannot be fully ascertained by strength testing. Thus, we do not know if pregnant women experience decrements to hip strength that could be contributing to their low back pain. Strength testing is safe postpartum, but to date no studies have been performed.

Therefore, the effect of pregnancy-related pain and asymmetries occurring postpartum has not been thoroughly studied. Specifically, the relationship between pelvic and lower extremity asymmetries and low back, pelvic, leg, and foot pain postpartum has not been investigated. Additionally, an assessment of the strength of hip musculature to determine the role of muscle strength in low back and lower extremity pain postpartum is warranted.

\section{Overview}

We compared three groups of participants: a control group of nulliparous women, women postpartum without pain, and women postpartum who report lingering pain following pregnancy. Postpartum women were tested between three months and two years following parturition. After consent was obtained, the subjects completed a pain survey using a visual analogue scale (VAS). The VAS will assess pain of the lower back, posterior pelvis, and lower extremities (15). Postpartum subjects with pain greater than three out of ten were placed in the postpartum pain group (15). Postpartum subjects with no pain or less than three out of ten on the VAS were placed in the postpartum no pain group. Subjects who have never given birth were the control group. Flexibility was compared between all three groups. We assessed the following measurements; pelvic obliquity (PO), foot length (FL), foot width (FW), rearfoot angle (RFA), arch drop (AD), arch index (AI), arch height index (AH), arch rigidity index (ARI), Beighton's test, Sit and Reach test, dynamic knee valgus, and hip abduction/adduction strength. 


\section{Specific Aims}

Specific Aim 1: To quantify foot, lower extremity, and pelvic asymmetries in women with low back, posterior pelvic, leg and foot pain postpartum and compare to a control group of nulligravida women and a postpartum no pain group. Specifically, we compared asymmetries in foot length, width, arch index, arch height index, arch rigidity index, arch drop, subtalar joint angle, leg length, dynamic knee valgus, pelvic obliquity, and hip strength in postpartum women in pain and not pain, and nulliparous control group. We also assessed flexibility using Beighton's test and the Sit and Reach test to compare the groups.

Hypothesis 1a: We hypothesized that women in the postpartum pain group would have increased asymmetries in arch drop, arch index, arch height index, subtalar joint angle, foot length, foot width, leg length, pelvic obliquity, dynamic knee valgus, and hip strength compared to the control group of nulligravida women and the postpartum women who are not in pain.

Hypothesis $1 b$ : We hypothesized that women postpartum in pain would have decreased flexibility and higher Beighton's scores.

Specific Aim 2: To examine the relationship between the biomechanical measurements of asymmetry and strength, and self-reported measures of foot, lower extremity, posterior pelvic, and lumbar spine pain in all subjects.

Hypothesis 2: We hypothesized that greater asymmetry is positively correlated with foot, leg, posterior pelvic, and lumbar spine pain in the study participants. 


\section{Background and Significance}

Relaxin, a hormone produced during pregnancy, is associated with increased ligamentous laxity of the sacroiliac joint and even peripheral joints (14). Many studies have reported pelvic pain and sacroiliac joint asymmetries during pregnancy $(14,19,20)$, but few have examined recently postpartum women (6) and even fewer looked at longer lasting pain (21).

Pregnancy results in permanent anthropometric changes to the foot such as increased foot length and width, and increased arch drop $(3,11,14)$. The increased body weight associated with pregnancy may also contribute to the collapse of the arch, as it is related to problems such as displacement of the hallux and arthritic degeneration that often requires surgery (12). This is a major concern, as there are risks associated with surgery and the necessary time needed for recovery.

Low back, pelvic, and foot pain are common during pregnancy $(13,14,22)$. Additionally, many postpartum women have reported lingering pregnancy-related pain. Ponnapula and Boberg (13) found that $42 \%$ of recently postpartum women experienced general foot pain during pregnancy. As previously stated, nearly $50 \%$ of women experience back pain during pregnancy (2), and this pain can persist postpartum (23). One in five pregnant women experience pelvic girdle pain, and a portion of those in the most pain during pregnancy developed chronic pain postpartum (7). Borkar and Mahishale (24) examined the prevalence of pregnancy-related pelvic girdle pain; they found more women report posterior pelvic pain. Despite these data, few studies have examined the relationship between back, pelvic leg, and foot pain and asymmetries in postpartum women.

There is minimal research that relates changes in lower extremity and pelvic alignment in postpartum women, and the relationship to self-reported pain of the low back, pelvis, and lower 
extremities. This study could potentially reveal factors that are associated to pregnancy-related chronic pain, and contribute to the development of preventative measures for pain.

\section{Assumptions}

In this study, assumptions were made in response to the subjective pain values in the questionnaires. It was assumed that all subjects truthfully and accurately qualified and quantified their pain. It was also assumed that the pain experienced during pregnancy and postpartum were solely the result of pregnancy. Finally, it was assumed that all biomechanical measured asymmetries did not exist prior to pregnancy; however, we qualified the nulliparous control group's asymmetries as the norm.

\section{Limitations}

Limitations of this study involve lifestyle factors that cannot be controlled such as physical activity and the subjects' overall health, including mental health, that could affect pain. We were not able to assess the subjects' asymmetries prior to pregnancy, so all the asymmetries may not be related to pregnancy. Although, we assessed the normal levels of asymmetries in the control group to use for comparison.

\section{Delimitations}

Postpartum women with and without pain were chosen for this study. The control group consisted of healthy, nulliparous women. If any in the control group had a history of prior miscarriage, then the cutoff for inclusion as a control subject was that the miscarriage had to occur prior to eight weeks gestation. We limited the subjects to a maximum of two years postpartum to exclude other health problems that may be related to pain that was not associated with pregnancy. 


\section{Definitions}

Arch drop (AD)- Sitting arch height minus the standing arch height

Arch index (AI)- Ratio of the midfoot area to the total foot contact area (excluding the toes) Arch height index (AHI)- Ratio between foot height and the truncated foot length, from the back of the heel to the head of the of the first metatarsal

Arch rigidity index (ARI)- Ratio between the sitting arch height index and the standing arch height index

Multigravida- A woman who is or was pregnant more than once

Nulliparous- A woman who has never given birth

Nulligravida- A woman who has never been pregnant

Pelvic Obliquity (PO)- Deviation of the pelvis from the horizontal in the frontal plane

Pelvic Torsion- Unilateral rotation of the pelvis in the sagittal plane

Primigravid- A woman who is pregnant for the first time

Rearfoot angle (RFA)- Angle between the leg and posterior calcaneus while standing, in the frontal plane 


\section{Chapter 2: Literature Review}

\section{Pain During and After Pregnancy}

Women experience foot, lower extremity, pelvic and low back pain during and after pregnancy $(8,13,22)$. About fifty percent of pregnant women experience back pain (2), which mainly occurs in the third trimester (16). Notably, Olsson et al. (6) found that nearly $30 \%$ of postpartum women continued to experience lumbopelvic pain at six months postpartum. Sixteen to thirty-eight percent of pregnant women with severe back pain reported that the pain had persisted six months to six years postpartum $(6,22)$, and in some cases the pain persisted into older adulthood (16).

One in five pregnant women experience pelvic pain, and about a quarter of these women develop chronic pain postpartum (7). Ostgaard et al. (2) reported one out of every three pregnant women have posterior pelvic pain (PPP). More women have posterior than anterior pelvic pain, as $65 \%$ of women reported posterior pelvic pain compared to $15 \%$ with anterior pelvic pain (24).

The foot is also a common site of reported postpartum pain. Women who are postpartum experienced more leg and foot pain compared to nulliparous women (i.e. never given birth) (8). Forty-two percent of recently postpartum women reported foot pain (13). This pain is not site specific within the foot (13).

The influence of previous pregnancies on pain is debated. Lingren and Kristiansson (16) studied the relationship between finger joint laxity and pregnancy-related back pain in postpartum women, and found the larger the abduction angle of the fourth left finger and higher numbers of pregnancies were related to an increased level of back pain. On the contrary, Mahishale and Borkar (24) reported that about 55\% of primiparous women complained of low back pain during pregnancy compared to $13 \%$ multiparous and $4 \%$ grand multiparous women, or 
women who have given birth to five or more children. They also reported that $70 \%$ of primiparous women complained of posterior pelvic pain, while only about a quarter of multiparous and $4 \%$ grand multiparous women experienced posterior pelvic pain during pregnancy (24).

As part of the body's natural preparation for childbirth, the hormone Relaxin increases the laxity of the pubic symphysis and sacroiliac joints to better allow the mother's body to give birth (10). Peripheral joint ligaments also develop increased laxity from the effects of Relaxin (10). Notably, this increased pelvic and peripheral laxity is a likely contributor to the pain reported during pregnancy and postpartum. Pelvic pain and increased laxity are both associated with increased serum concentrations of Relaxin (25). Increased joint laxity is correlated with low back pain (16).

\section{Relaxin and Pregnancy}

Relaxin is a peptide hormone found in the serum of pregnant women (26). It is secreted by the corpus luteum in early pregnancy and by the ovaries during the luteal phase of menstruation (26). Relaxin directly stimulates architectural integrity of connective tissue, which depends on a delicate balance of the matrix metalloproteinases and the endogenous tissue inhibitors of metalloproteinases (27). Relaxin leads to a distinct decline in the total collagen content because of the reduction in the density and organization of collagen bundles (5). These changes to collagen can precipitate changes to the ligamentous laxity $(5,26)$. Estrogen may also play a role in the ligamentous tissue integrity (26), and may control the expression of Relaxin receptors because estrogen priming increases the release of Relaxin and the target organ's response to Relaxin (26). 
Also, Relaxin directly affects the blood vessels by inducing vasodilation (28), and this may be why some women have preterm births. Elevated concentrations of Relaxin in women during pregnancy is associated with preterm birth, and there is increased insulin resistance with the lack of circulating Relaxin (27). Several studies have related the level of reported low-back pain and the circulating serum levels of Relaxin in pregnant women; however, they have conflicting results $(7,25)$.

\section{Changes in Foot Structure During Pregnancy}

Due primarily to the influence of Relaxin on the intrinsic ligaments of the foot, women experience many changes to the foot structure during pregnancy. Multiple studies report increased arch drop during weight bearing, and increased foot length, width, and volume in pregnant women $(3,11,12)$. Several studies have reported significant increases in foot length in primigravid women with the changes persisting postpartum $(11,29)$. While Ponnapula and Boberg (13) anecdotally reported increased foot width during pregnancy, these data were not significant, which coincides with Harrison (29) who also found no significant change in foot width.

Alvarez et al. (30) noted a significant change in foot volume during pregnancy. There was a small reduction in foot volume postpartum, although the volume did not return to the prepregnancy value (30). The authors attributed this increase in volume to lower extremity swelling because of fluid retention rather than bony or ligamentous changes (30).

Increase in body mass, either from pregnancy or obesity, is associated with a decrease in arch height, which can result in pes planus or "flat foot" (12). The increase in body mass also increases the surface area of the foot, but mainly the rearfoot (3). This is most likely from the increase of abdominal mass in pregnant women, which makes them shift more of their weight 
posteriorly onto their heels (11). This increase in surface area during pregnancy also contributes to the increased foot length (3).

The greatest changes of the foot are observed in the first pregnancy $(5,11)$. Primiparous women display the greatest reduction in arch rigidity and arch drop, and increase in foot length (5). Arch height index and arch rigidity index also decreased more significantly in primiparous women than those with a history of previous pregnancy (5).

\section{Changes in Lower Leg Alignment}

A significant relationship exists between rearfoot angle (RFA) during quiet stance and arch drop (31). Rearfoot angle is the frontal plane angle between the lower leg and posterior calcaneus while standing when viewed posteriorly. The ligamentous laxity of the plantar calcaneonavicular (spring) ligament and attenuation of the tibialis posterior tendon can lower the first metatarsal head and create a more pronated foot (32). However, although increases in arch drop are noted in pregnancy $(11,12)$, Harrison (29) and Casto (15) reported no significant changes in rearfoot angle during pregnancy. No change of the RFA indicates no increase in foot pronation relating to a decrease in arch height (29), thus the decrease in arch height (AH) is likely indicative of changes to bony structure and ligamentous arch support. Examination of rearfoot angle in postpartum women has not been thoroughly investigated.

\section{Changes in Pelvic Alignment}

During pregnancy, increased mobility of the sacroiliac joints and widening of the pubic symphysis are caused by an increase in ligamentous laxity, likely attributable to Relaxin (33). In non-pregnant individuals who report low-back pain, no significance was discovered between prevalence of postural asymmetry in regard to low back pain when assessing pelvic obliquity (34). Pelvic obliquity (PO) is the tilting of the pelvis in the frontal plane, and can be caused by 
either leg length discrepancy or pelvic asymmetry. Fann (34) reported using heel lifts to correct PO for people with chronic back pain, even though PO was similar in participants with and without low back pain. Interestingly most patients who completed the heel lift study reported decreased pain despite the fact that no differences in $\mathrm{PO}$ were noted between individuals in pain and those not in pain (34).

In a study on pelvic alignment in pregnant women, Harrison (29) reported that nonpregnant controls tended to have greater pelvic obliquity than the pregnant group over the three trimesters, but the analysis could not decipher which groups were significantly different. Casto (15) found no trend or significance for pelvic asymmetry between pregnant women in pain and those not in pain. Casto (15) also measured iliac crest height in a seated position to remove leg length discrepancy, and found no significance between pregnant women in pain, pregnant women not in pain, and nulliparous controls for the even and uneven iliac crest heights. The majority of these studies have small sample sizes, so trends may be significant in a larger subject pool.

\section{Asymmetry and Pain}

There is a strong correlation between pelvic asymmetry, tibial and femoral length asymmetry, and reported low back pain during pregnancy (13). The data of Harrison (29) provides support for the relationship of asymmetry and musculoskeletal pain. Left-right arch rigidity index (ARI) asymmetry was correlated to pain in the upper knee and leg pain, and arch index asymmetry was correlated with overall lower extremity pain during pregnancy (29). Casto (15) reported a trend towards a higher ARI asymmetry in pregnant women, but cautioned that measurements may be affected by swelling during pregnancy. 


\section{Exercise and Pregnancy}

Exercising can be beneficial during pregnancy because it is related to improvement of the cardiovascular system, curtailed weight gain, reduced edema and cramping, a lower likelihood of gestational diabetes and hypertension, confidence and self-esteem (18). However, in regard to reported pain in pregnancy, the results are less promising. Authors have reported no significance in pain reduction following exercise intervention programs in pregnancy (35). Dumas et al. (36) reported no significant differences on spinal posture. Following an exercise intervention for pregnant women, a significant increase in pain was noted between the first and third trimesters. A comparison between pregnant non-exercisers (i.e. the control group) and those who received the exercise treatment, revealed no reduction of back pain with exercise at various time points during pregnancy (35). However, exercise may prove beneficial at treating pain in the long-term, as although back pain still increased in the exercise group during pregnancy, it was significantly decreased postpartum compared to the control group (35). Unsgaard-Tondel et al. (37) reported a reduction in pain intensity and decreased disability over the time of the intervention in women reporting low back and pelvic pain postpartum. Studies that examined exercise programs on lumbopelvic pain in postpartum women have found that exercise may be effective in relieving pain (38).

\section{Hip Strength, Leg Alignment, and Leg Pain}

The strength of the hip musculature may be associated with knee pain and excessive frontal plane loads across the knee joint in normal non-pregnant individuals, and thus also must be considered as a source of postpartum pain (39). Anterior knee pain is quite common in women. However, the percentage of prevalence is still debated in women with knee pain, but a study from 2012 reported a prevalence rate of $12-13 \%$ for anterior knee pain in females (40). 
Rowe et al. (39) suggests that people with knee pain have weak hip musculature, particularly as it relates to the frontal plane. A significant decrease in strength was seen when comparing the strength of the gluteus medius muscle of the affected side compared to the non-affected gluteus medius muscle; there was also a reduction of strength of the affected-side gluteus maximus muscle compared to the unaffected side (39). Thus, the strength of the gluteus muscles may play a role in lower extremity alignment (39).

Arab et al. (17) examined hip abduction muscle strength in individuals with and without IT band tightness who report low back pain compared to a healthy control group who did not report pain. They found that regardless of IT band tightness, participants with low back pain had significantly weaker hip abductor muscles than the control subjects (17). Niemuth et al. (41) investigated hip muscle weakness and injuries in recreational runners, and postulated that hip muscle weakness contributed to uncontrolled femoral adduction and internal rotation, thus increasing the dynamic Q angle. They found that hip flexors and abductors were significantly weaker in the injured lower extremity, while the hip adductors were significantly stronger in the injured lower extremity (41). The quadriceps (Q) angle provides information for alignment of the knee and can be useful for determining maltracking of the patella (39). Maltracking of the patella is often associated with anterior knee pain (42).

Several studies suggest that the Q angle is a combination of measurements for pelvic, patella and foot position as well as hip and tibial rotation $(42,43)$. Excessive anterior pelvic tilt, femoral anteversion and knee valgus, and external rotation of the tibia may contribute to an increase in Q angle (43). Nguyen et al. (43) reported significance for greater tibiofemoral angle and femoral anteversion as predictors of increased Q angle in not just females, but males too. Another study investigated the relationship between joint hypermobility and Q angle, but as 
females have greater hypermobility than males, the researchers only evaluated male subjects (42). Individuals with Beighton scores of five or higher, which is indicative of hypermobility, have significantly greater $\mathrm{Q}$ angles when compared to a group with a Beighton score of zero (42). Knee valgus is an important measurement contributing to $Q$ angle. Static $Q$ angle is not as clinically relevant as a dynamic measurement of knee valgus. An increased knee valgus is associated with increased knee injuries (44).

\section{Spinal Posture During Pregnancy and Postpartum}

Postural adaptions that became habitual during pregnancy may continue postpartum (45). During sitting, postural alignment was not significantly different between pregnant, postpartum or non-pregnant women (45). However, during standing, the postpartum women had reduced sagittal plane anterior orientation of the pelvis $(\mathrm{p}=0.01)$, meaning these women had less forward pelvic tilt. They also had a smaller extension of the thoracolumbar spine $(\mathrm{p}=0.003)$, which demonstrates a flatter spinal curve (45). The changes of the pelvic segment and thoracolumbar spine during standing may be indicative of imbalances of postural muscles.

Foot, lower extremity, pelvic, and back pain are all common problems during pregnancy $(8,13,22)$, but women are still experiencing pain months postpartum $(6-8,13)$. Pregnancy also leads to lasting changes of foot dimensions $(11,13)$. Relaxin is the hormone mainly responsible for increased ligamentous laxity during pregnancy (10), which influences peripheral joints, and may be related to pelvic and low back pain (16). Some studies reported a significant change in lower leg alignment, such as arch drop, but found no significant changes in rearfoot angle (15, 29).

Based on the number of postpartum women still experiencing pain, biomechanical measurements of alignment need to be further assessed on the pelvis and lower extremities. 
Increased Q angle and knee valgus are related to pain and are seen in individuals that are hypermobile, which is why flexibility needs to be evaluated in postpartum women. It is important to examine if there are any relationships between malalignment, strength, and pain in postpartum women because of the limited literature on this particular group of women. 


\section{Chapter 3: Methods}

\section{General Outline}

We recruited women who were between six months and two years postpartum and nulliparous controls. Data were collected at West Virginia University. After consent was obtained, participants were given a visual analog scale (VAS) pain questionnaires to assess pain in their feet, lower extremities, posterior pelvis, and lumbar spine. Postpartum subjects were categorized into a postpartum pain group or no pain group based on measurements from the VAS questionnaire. Measures of lower extremity alignment and asymmetry were collected bilaterally on the lower extremities. Subjects also performed hypermobility and muscular flexibility tests, and strength was assessed of the hip musculature. Only one visit was necessary for data collection for each subject.

\section{Subjects}

We recruited 24 women, ages 24-37, from the Morgantown area to participate in this study. The postpartum pain group had seventeen women, and eight in the no pain postpartum group. The control group had seven nulliparous women. These women were recruited from the Morgantown, West Virginia area by word of mouth. Flyers were placed in the WVU Health Sciences Center and WVU healthcare facilities. Postpartum women were recruited from local Mommy and Me classes, daycares, etc. The first group was healthy nulliparous control, second was a postpartum no pain with a VAS of $<3 / 10$, and the third was a postpartum group with pain graded as $\geq 3 / 10$ on the VAS. Postpartum women were included regardless of the number of pregnancies.

Exclusion criteria included: lower extremity injuries such as Achilles tendinitis, sprains, or fractures within the past year, chronic pain or malalignment unrelated to pregnancy (e.g. 
scoliosis, etc.), women who miscarried after eight weeks gestation, women who most recently gave birth more than two years ago, low back or hip pain prior to pregnancy. Also, subjects were excluded if they had a history of a condition affecting sensation, if they smoked, had diabetes, or connective tissue disorders. All subjects were screened for participation via telephone or email.

The postpartum pain group was significantly $(\mathrm{p}=0.015)$ older than the control group. No other differences were noted between the groups for the other demographic variables (Table 1). Table 1: Subject Demographics

\begin{tabular}{|c|c|c|c|c|c|}
\hline & N & Age(yrs.) & Ht(cm) & Mass(kg) & \# Pregnancies \\
\hline Postpartum Pain & 9 & $\mathbf{3 2 . 4} \pm \mathbf{3 . 3 *}$ & $163.8 \pm 7$ & $81.0 \pm 24.0$ & $2 \pm 1$ \\
\hline Postpartum & 8 & $30.1 \pm 3$ & $167 \pm 8$ & $72.1 \pm 17.3$ & $2 \pm 1$ \\
No Pain & & & & & \\
\hline Control & 7 & $\mathbf{2 7 . 6} \pm \mathbf{3}^{*}$ & $161.1 \pm 5.7$ & $71.0 \pm 14.3$ & 0 \\
\hline
\end{tabular}

*Represents significance, $\mathrm{p}<0.05$

\section{Procedures}

\section{Informed Consent}

Data collection took place in the Human Performance Lab on the $8^{\text {th }}$ floor of WVU's Health Sciences Center. The procedures were verbally explained, and the subjects were encouraged to ask questions, following this, written informed consent was obtained. This study was approved by WVU's Institutional Review Board for the Protection of Human Subjects (Appendix A). Subjects were encouraged to ask questions throughout the consenting process and during data collection. Following consent, subjects were asked to change into close-fitting attire and to remove any socks or shoes. 


\section{Pain Assessments}

The subjects completed a questionnaire that assessed current self-reported pain bilaterally on the lower extremities using a visual analog scale (VAS). This questionnaire design was based on the previously validated VAS Foot and Ankle (Appendix B) (46). There were six questions for each site of pain; lower back (LB), hip and buttocks (HB), upper right leg (URL), upper left leg (ULL), right knee (RK), left knee (LK), lower right leg (LRL), lower left leg (LLL), right ankle/foot (RAF), and left ankle/foot (LAF). The VAS scale is a $10 \mathrm{~cm}$ long horizontal line that starts at 10 on the left and ends at zero on the right. Zero is no pain and ten is the worst pain possible. Subjects marked the line to indicate the severity of their pain. Measurements were taken to the nearest millimeter. Scores were added from each location and averaged by six to get a total score out of ten for each site. Subjects with scores less than 3/10 were in the no pain control group and postpartum no pain group, and scores greater or equal to 3/10 were in the postpartum pain group (15).

\section{Biomechanical Assessment}

Subjects' age, height, and number of pregnancies were evaluated (Appendix C, Appendix D). Participants were asked to remove their shoes, and their weight was measured using a standard scale (2020W Mechanical Rotating Dial Scale, Taylor Precision Products, Oak Brook, IL). Biomechanical measurements were evaluated using an anthropometer to assess pelvic, lower extremity, and foot alignment (Lafayette Instrument Company, Model 01291). All measurements were taken bilaterally on the subjects, and the left or right lower extremity was randomly selected to assess first (Appendix C).

Foot width (FW) was measured with the subject standing in an upright position and feet shoulder width apart using a standard anthropometer (Lafayette Instrument Company, Model 
01291). Foot width was defined as the distance between the most medial and lateral portions of the forefoot (Intrarater reliability Pearson correlation coefficient: $>0.907)$. Following this, measurements were taken of the contralateral foot. These measurements were recorded in centimeters.

We employed the Arch Height Index Measurement System (AHIMS) using sliding calipers (JAK Tool, New Jersey, New York) to measure foot length (FL), truncated foot length (TFL), and foot height (FH). The subject was seated with each foot elevated on two wooden blocks such that the medial longitudinal portion of the arch was unsupported. The AHIMS calipers were then placed around the foot. Foot length was measured from the most anterior to the most posterior aspects of the foot. Truncated foot length was measured as the distance from the head of the first metatarsal to the most posterior aspect of the heel. Foot height was the height of the dorsum of the foot at half of the total foot length. A goniometer was used to ensure the line of the lateral ankle and fifth metatarsal head formed a $120^{\circ}$ angle with the line from the lateral ankle to the fibular head. Measurements were taken when the subject was first seated and then standing. Based on these measurements, calculations were made for arch height index (AHI) when standing and seated, arch rigidity index (ARI), and arch drop (AD). Higher AHI indicated a higher arch. ARI values near one indicated a rigid arch, and values closer to zero were more flexible arches. Higher arch drop values mean the arch was more flexible.

$$
\begin{aligned}
& \text { seated } A H I=\frac{\text { seated } F H}{\text { seated } T F L} \quad \text { standing } A H I=\frac{\text { standing } F H}{\text { standing } T F L} \\
& A D=\text { seated } F H-\text { standing } F H \quad A R I=\frac{\text { standing } A H I}{\text { seated } A H I}
\end{aligned}
$$


Arch index (AI), measured via an inked footprint, was an indirect measurement of arch height. AI was assessed based on methods validated by Cavanagh and Rodgers (47). (Intrarater reliability Pearson correlation coefficient: $>0.887)$. Arch index was measured by distributing half of the subject's body weight onto one foot that is situated on an inkpad (Aetrex Harris Mat, Dedham, Massachusetts), with her feet $15 \mathrm{~cm}$ apart. A thin rubber bladder was located between the foot and inkpad, so no ink came into contact with the skin. A standard scale (2020W Mechanical Rotating Dial Scale, Taylor Precision Products, Oak Brook, IL) was used to indicate when $50 \%$ of the subject's body weight is on the scale, and $50 \%$ was on the inkpad. Both the left and right feet were assessed. Area of the footprint was calculated using NIH software ImageJ (NIH, Bethesda, MD). Subsequently, a straight line was drawn on the footprint from the tip of the second toe to the most posterior aspect of the foot. We measured the distance from the most anterior aspect of the metatarsals to the posterior portion of the calcaneus. That distance was then divided into three sections, indicating the forefoot, midfoot, and rearfoot. The area of the midfoot was then be determined using Image $J$ software. Arch index was defined as the area of the midfoot divided by the total area of the footprint (47). AI between 0.21 and 0.26 was a normal arch. Less than 0.21 was considered a high arch (pes cavus), and greater than 0.26 was considered a low arch (pes planus) (47).

Dynamic knee valgus was evaluated using a single leg step-down. The movement was recorded using Hudl (Agile Sports Technologies, Inc. Lincoln, NE), which captures the movement in slow motion. Procedures followed those used by Hollman et al. (44) for joint alignment. The camera was placed $3 \mathrm{~m}$ from the frontal view of the subject at knee level. The knee valgus/varus angle was measured using the line connecting the ASIS to the midpoint of the tibiofemoral joint and a second line bisecting the tibiofemoral joint and the talocrural joint (44). 
Knee valgus was assessed bilaterally, and familiarization was given. The subject was instructed to stand on a $15 \mathrm{~cm}$ box, stand in a single leg stance for two seconds and then step down onto their heel over two seconds before returning to the starting position. Measurements were taken at the starting position as a baseline and when the knee angle was at its greatest.

Next, neuromuscular flexibility was measured using the Trunk flexion test, which is commonly known as the Sit and Reach test (48). The test was performed using the Canadian version per ACSM guidelines (48). Subjects positioned their knees fully extended, with feet flat against the box with the medial portion of their foot within $2 \mathrm{~cm}$ of the measuring scale. Subjects slowly reached forward with both hands as far as possible, while making sure not to lead with one hand. Subject were required to hold the stretch for at least 2 seconds, and the best of two trials was scored.

Hypermobility was assessed using the Beighton Score (42). The Beighton score assesses five locations of flexibility: hyperextension at the knees, passive touching of the thumb to the forearm, passive dorsiflexion greater than 90 degrees of the little finger, hyperextension at the elbows, and flexion of the trunk with knees fully extended and palms flat on the floor. A point was given for each hand, elbow, and knee for each location of flexibility, except the forward flexion at the hips with palms on the floor where one point is given. A score of five or more out of the nine points was a positive Beighton score, which indicates hypermobility.

Rearfoot angle (RFA) was measured using Clarke's methods of photogrammetry (49).

RFA assessed calcaneal inversion and eversion. Subjects stood $15 \mathrm{~cm}$ apart, and a line was dropped from the midpoint of the knee joint of the dorsal side of the subject's legs at the musculotendinous areas of the gastrocnemius and Achilles tendon (15). Subjects kneeled on a chair holding the back, the subtalar joint was placed into a neutral position, and marks were 
made on the midpoint of the Achilles and top and bottom of the calcaneus (15). Next, the subject stood so posterior-view photographs could be taken.

Images were analyzed using ImageJ software. A line was drawn between the two markers on the posterior calf, and a second line between the two markers on the posterior heel. The rearfoot angle was defined as the angle between these two lines. Increased rearfoot angle indicated increased eversion.

Pelvic obliquity (PO) was the angle the pelvis made with the horizontal in the frontal plane. We measured pelvic obliquity using a palpation meter called the PALM (Performance Attainment Associates, Lindstrom, MN). PO was assessed by palpating the anterior and posterior superior iliac crests on the left and right sides, and placing reflective markers on these locations. We measured the distance in centimeters and inclination angle in degrees between the anterior superior iliac spines (ASISs), and the posterior superior iliac spines (PSISs). Also, ASIS-PSIS distances and inclination angles were assessed for pelvic torsion asymmetry. The tops of the iliac crests were palpated and measured using the PALM for height discrepancy while the subject was sitting and standing to determine pelvic asymmetry.

The subjects also participated in isokinetic muscle strength testing to assess strength of the hip abductors and adductors for both the dominant and nondominant thigh. This assessment was completed using the Biodex System 4 Isokinetic Dynamometer (Biodex, Medical Inc., Shirley, NY; Model number 835-000). We randomly selected the left or right thigh to go first. The subjects positioned their hip parallel to the dynamometer for hip abduction and adduction in the frontal plane. The greater trochanter of the femur was used to find the height of the anterior center of the hip, the point of rotation. That point was appropriately positioned to align with the dynamometer. The subjects performed 7 repetitions of maximal isokinetic hip abduction and 
adduction at $60^{\circ}$ per second. We examined peak torque for both hip abduction and adduction. Researchers made sure the subject did not lean laterally or forward, nor hike their hip up during the assessment to ensure appropriate positioning.

\section{Statistical Analysis}

Statistical analysis was performed using IBM SPSS Statistical software version 25

(Armonk, New York). We generated descriptive statistics, including measures of central tendency (e.g. means, medians) and dispersion (standard deviations and ranges) for age, weight, height, and number of pregnancies. A comparison of subject demographics between groups was performed via an ANOVA $(\alpha=0.05)$.

Specific Aim 1 was to quantify foot, lower extremity, and pelvic asymmetries in women with low back, posterior pelvic, lower extremity, and foot pain postpartum and compare to a control group of nulligravida women and a postpartum no pain group. Specifically, we compared asymmetries in foot length, width, arch index, arch height index, arch rigidity index, arch drop, subtalar joint angle, dynamic knee valgus, leg length, pelvic obliquity, and hip strength in postpartum women in pain and not pain, and nulliparous control group. We also assessed hypermobility and muscular flexibility using Beighton's test and the Sit and Reach test to compare the groups. Hip abduction and adduction strength were compared between the groups. We used an ANOVA to compare the variables in Aim 1 between the three groups.

Specific Aim 2 was to examine the relationship between the biomechanical measurements of alignment and strength, and self-reported measures of foot, lower extremity, posterior pelvic, and lumbar spine pain in all subjects. To accomplish this, correlation analysis using Spearman-Rho non-parametric analysis were performed for each dependent variable. We selected Spearman-Rho tests, a non-parametric analysis, because previous studies $(15,29)$ have 
revealed non-normally distributed data for the pain scales due to a ceiling effect for "no pain" responses. The Alpha level for each analysis was set to 0.05 a priori. 


\section{Chapter 4: Results}

\section{Description of Postpartum Pain}

In this study, the post-partum women were at least six months to up to a maximum of 24 months postpartum to reduce the possibility that the pain was unrelated to pregnancy. We had a total of 24 subjects: 9 postpartum women in pain, 8 postpartum women no pain, and 7 nulliparous controls. To evaluate a subject's pain, we used the VAS questionnaire, and anything measured greater than $3 \mathrm{~cm}$ was considered pain. None of the postpartum no pain nor controls reported any significant pain in any of the six locations. Seven postpartum women reported low back pain. Five women reported hip pain, which approximately $56 \%$ of postpartum women in pain reporting hip pain. Only one subject reported thigh and leg pain. Twenty-two percent of the women stated pain existed at the knee. Almost $45 \%$ of the women in pain reported pain at the foot and ankle.

\section{$\underline{\text { Specific Aim 1: }}$}

The first specific aim was to compare asymmetries on the dependent variables between post-partum women with lingering pregnancy related pain, post-partum women who do not report pain, and never pregnant controls. Few variables were significantly different between the groups. A trending significant difference exists for foot width asymmetry between the three subject groups ( $p=0.099)$. A Tukey post hoc test further showed that the significance was between the postpartum no pain group and the controls, and that women in the no pain group had larger foot widths than the controls $(\mathrm{p}=0.089)$. Another significant difference between the groups was the average peak abduction torque. A post hoc analysis revealed that the postpartum no pain group had significantly greater abduction torque than the controls $(\mathrm{p}=0.057)$. 
No significance was found between the groups for measurements of the ASISs, degree of tilt between the ASISs, distance between the PSISs, and degree of tilt between the PSISs. Iliac crest height standing or sitting was not significant. Additionally, the degree of pelvic tilt of the iliac crest at standing or seated was not significant (Table 4). The other variables in Tables 2-4, when compared between each three groups were not significant. As shown in Table 5, there was no significant difference between the three groups for Beighton's hypermobility test $(\mathrm{p}=0.15)$ or the Sit and Reach test $(\mathrm{p}=0.699)$. 
Table 2: Foot Asymmetry values in the three subject groups. Data shown are mean \pm standard deviation.

\begin{tabular}{|c|c|c|c|c|}
\hline & Postpartum Pain & Postpartum No Pain & Control & p-value \\
\hline FW $(\mathrm{cm})$ & $0.2 \pm 0.18$ & $0.33 \pm 0.18$ & $0.13 \pm 0.14$ & $\mathbf{p}=\mathbf{0 . 0 9 9}$ \\
\hline FL sit $(\mathrm{cm})$ & $0.13 \pm 0.07$ & $0.33 \pm 0.21$ & $0.24 \pm 0.30$ & $\mathrm{p}=0.182$ \\
\hline FL stand (cm) & $0.18 \pm 0.08$ & $0.29 \pm 0.23$ & $0.23 \pm 0.25$ & $\mathrm{p}=0.522$ \\
\hline TFL sit (cm) & $0.17 \pm 0.11$ & $0.21 \pm 0.22$ & $0.29 \pm 0.35$ & $\mathrm{p}=0.619$ \\
\hline TFL stand (cm) & $0.19 \pm 0.19$ & $0.20 \pm 0.15$ & $0.17 \pm 0.14$ & $\mathrm{p}=0.944$ \\
\hline FH sit (cm) & $0.13 \pm 0.16$ & $0.28 \pm 0.16$ & $0.31 \pm 0.28$ & $\mathrm{p}=0.180$ \\
\hline FH stand (cm) & $0.16 \pm 0.11$ & $0.23 \pm 0.12$ & $0.24 \pm 0.23$ & $\mathrm{p}=0.499$ \\
\hline AHI sit & $0.01 \pm 0.01$ & $0.02 \pm 0.01$ & $0.02 \pm 0.02$ & $\mathrm{p}=0.219$ \\
\hline AHI stand & $0.01 \pm 0.01$ & $0.06 \pm 0.01$ & $0.02 \pm 0.01$ & $\mathrm{p}=0.715$ \\
\hline AD & $0.11 \pm 0.06$ & $0.08 \pm 0.07$ & $0.10 \pm 0.06$ & $\mathrm{p}=0.502$ \\
\hline ARI & $0.02 \pm 0.01$ & $0.02 \pm 0.01$ & $0.02 \pm 0.02$ & $\mathrm{p}=0.837$ \\
\hline AI & $0.02 \pm 0.01$ & $0.04 \pm 0.03$ & $0.03 \pm 0.03$ & $\mathrm{p}=0.133$ \\
\hline
\end{tabular}


Table 3: Lower Extremity Asymmetry values in the three subject groups. Data shown are mean \pm standard deviation.

\begin{tabular}{|c|c|c|c|c|}
\hline & Postpartum Pain & Postpartum No Pain & Control & p-value \\
\hline Leg length (cm) & $0.63 \pm 0.48$ & $0.41 \pm 0.53$ & $0.59 \pm 0.79$ & $\mathrm{p}=0.736$ \\
\hline RFA & $5.66 \pm 3.24$ & $6.66 \pm 4.84$ & $7.74 \pm 5.14$ & $\mathrm{p}=0.651$ \\
\hline $\begin{array}{c}\text { Knee angle } \\
\text { diff(deg) }\end{array}$ & $6.94 \pm 4.97$ & $9.30 \pm 9.31$ & $7.20 \pm 5.58$ & $\mathrm{p}=0.753$ \\
\hline $\begin{array}{c}\text { ABD Avg pk } \\
\text { torque (Nm/kg) }\end{array}$ & $0.16 \pm 0.08$ & $0.18 \pm 0.05$ & $0.09 \pm 0.07$ & $\boldsymbol{p}=\mathbf{0 . 0 5 8}$ \\
\hline $\begin{array}{c}\text { ADD Avg pk } \\
\text { torque (Nm/kg) }\end{array}$ & $0.16 \pm 0.16$ & $0.19 \pm 0.12$ & $0.18 \pm 0.12$ & $\mathrm{p}=0.895$ \\
\hline
\end{tabular}

Table 4: Pelvic Asymmetry in three subject groups. Data shown are mean \pm standard deviation.

\begin{tabular}{|c|c|c|c|c|}
\hline & $\begin{array}{c}\text { Postpartum } \\
\text { Pain }\end{array}$ & $\begin{array}{c}\text { Postpartum } \\
\text { No Pain }\end{array}$ & Control & p-value \\
\hline ASISs (cm) & $26.37 \pm 7.34$ & $25.43 \pm 6.69$ & $25.40 \pm 2.15$ & $\mathrm{p}=0.933$ \\
\hline ASISs (deg) & $0.78 \pm 0.67$ & $1.38 \pm 0.74$ & $0.86 \pm 0.90$ & $\mathrm{p}=0.254$ \\
\hline PSISs (cm) & $14.54 \pm 4.0$ & $14.51 \pm 5.25$ & $11.56 \pm 1.89$ & $\mathrm{p}=0.282$ \\
\hline PSISs (deg) & $1.06 \pm 0.73$ & $1.63 \pm 1.996$ & $1.00 \pm 0.82$ & $\mathrm{p}=0.585$ \\
\hline ASIS-PSIS (cm) & $0.67 \pm 0.46$ & $1.04 \pm 0.96$ & $0.47 \pm 0.44$ & $\mathrm{p}=0.261$ \\
\hline ASIS-PSIS (deg) & $1.67 \pm 1.32$ & $1.75 \pm 0.89$ & $1.00 \pm 0.82$ & $\mathrm{p}=0.346$ \\
\hline Iliac crest stand (cm) & $27.233 \pm 3.60$ & $26.56 \pm 2.21$ & $26.19 \pm 2.69$ & $\mathrm{p}=0.770$ \\
\hline Iliac crest stand (deg) & $1.22 \pm 1.20$ & $1.13 \pm 0.84$ & $0.29 \pm 0.49$ & $\mathrm{p}=0.121$ \\
\hline Iliac crest sit (cm) & $27.62 \pm 4.06$ & $26.20 \pm 2.56$ & $25.94 \pm 2.63$ & $\mathrm{p}=0.531$ \\
\hline Iliac crest sit (deg) & $1.50 \pm 1.12$ & $0.75 \pm 0.89$ & $0.57 \pm 0.79$ & $\mathrm{p}=0.398$ \\
\hline
\end{tabular}


Table 5: Beighton, and Sit \& Reach Asymmetry in three subject groups. Data shown are mean \pm standard deviation.

\begin{tabular}{|c|c|c|c|c|}
\hline & Postpartum Pain & Postpartum No Pain & Control & p-value \\
\hline Beighton & $3.78 \pm 1.99$ & $2.50 \pm 2.07$ & $1.86 \pm 1.68$ & $\mathrm{p}=0.150$ \\
\hline Sit \& Reach $(\mathrm{cm})$ & $26.67 \pm 13.53$ & $28.63 \pm 9.02$ & $31.14 \pm 6.26$ & $\mathrm{p}=0.699$ \\
\hline
\end{tabular}

Specific Aim 2:

The second specific aim of this study was to examine the relationship between asymmetry and pain on the measured variables. Seated foot length asymmetry was negatively correlated to thigh pain $(\mathrm{p}=0.021)$ such that increased foot length asymmetry while seated was related to decreased thigh pain. Foot length asymmetry when seated was trending towards a significant correlation with low back, knee, and leg pain $(\mathrm{p}=0.078, \mathrm{p}=0.089, \mathrm{p}=0.079)$, so increased foot length asymmetry was related to decreased pain in the low back, knee and leg. Trending towards a negative relationship was standing truncated foot length with knee and leg pain $(\mathrm{p}=0.089, \mathrm{p}=0.079)$

A trending negative correlation exists between seated foot height asymmetry and low back and hip pain ( $\mathrm{p}=0.088, \mathrm{p}=0.084)$, such that decreased seated foot height asymmetry was related to increased low back and hip pain. Standing foot height asymmetry and hip and knee pain were negatively correlated $(\mathrm{p}=0.021, \mathrm{p}=0.037$ ), so decreased standing foot height asymmetry is related to increased hip pain. Trending towards a negative correlation was standing foot height asymmetry and thigh pain $(\mathrm{p}=0.066)$, so increased thigh pain was related to decreased standing foot height asymmetry. Seated arch height index asymmetry and low back and hip pain were negatively correlated $(\mathrm{p}=0.044, \mathrm{p}=0.040)$, thereby increased arch height index while seated is related to decreased low back and hip pain. Arch height index when standing was negatively 
correlated to hip, thigh, and knee pain $(\mathrm{p}=0.035, \mathrm{p}=0.025, \mathrm{p}=0.028)$, meaning increased standing arch height index was related to decreased hip, thigh and knee pain. A positive trend existed between arch rigidity index and foot/ankle pain $(p=0.074)$.

The asymmetry of the distance between ASIS-PSISs was a trending positive correlation $(p=0.065)$ to hip pain. Increased asymmetry of pelvic torsion was related to increased hip pain. Trending towards a positive relationship was the asymmetry of pelvic torsion angle with low back and thigh pain. A positive correlation was discovered for asymmetry of the difference in knee angle to leg pain $(\mathrm{p}=0.026)$, and a positive trend was present with knee pain. Increased knee angle asymmetry was related to increased leg pain. A negative correlation exists between the average peak hip adduction torque asymmetry and thigh, knee, and leg pain $(p=0.044, p=0.050$, $\mathrm{p}=0.046)$, and a negative trend for foot/ankle pain $(\mathrm{p}=0.061)$. Increased peak hip torque was related to decreased thigh, knee, and leg pain. All other variables were not significant. 
Table 6: Correlations for Foot Asymmetry at the low back, hip and thigh.

\begin{tabular}{|c|c|c|c|c|c|c|}
\hline & \multicolumn{6}{|c|}{ Pain Location } \\
\hline & \multicolumn{2}{|c|}{ Low Back } & \multicolumn{2}{|c|}{ Hip } & \multicolumn{2}{|c|}{ Thigh } \\
\hline & $\mathrm{R}$ & p-value & $\mathrm{R}$ & p-value & $\mathrm{R}$ & p-value \\
\hline FW & 0.103 & 0.633 & 0.037 & 0.865 & -0.085 & 0.694 \\
\hline FL sit & -0.366 & 0.078 & -0.342 & 0.102 & -0.467 & $0.021 *$ \\
\hline FL stand & -0.126 & 0.559 & -0.328 & 0.117 & -0.341 & 0.103 \\
\hline TFL sit & -0.235 & 0.270 & -0.108 & 0.616 & -0.178 & 0.405 \\
\hline TFL stand & -0.241 & 0.256 & -0.169 & 0.431 & -0.262 & 0.216 \\
\hline FH sit & -0.356 & 0.088 & -0.359 & 0.084 & -0.309 & 0.141 \\
\hline FH stand & -0.302 & 0.152 & -0.47 & $0.021 *$ & -0.382 & 0.066 \\
\hline AHI sit & -0.415 & $0.044 *$ & -0.422 & $0.040 *$ & -0.273 & 0.196 \\
\hline AHI stand & -0.237 & 0.265 & -0.432 & $0.035 *$ & -0.457 & $0.025 *$ \\
\hline $\mathrm{AD}$ & 0.073 & 0.736 & 0.062 & 0.775 & 0.018 & 0.934 \\
\hline ARI & 0.104 & 0.630 & -0.350 & 0.870 & 0.046 & 0.831 \\
\hline AI & -0.182 & 0.395 & 0.126 & 0.558 & 0.024 & 0.913 \\
\hline
\end{tabular}


Table 7: Correlations for Foot Asymmetry at the knee, leg, and foot/ankle.

\begin{tabular}{|c|c|c|c|c|c|c|}
\hline \multirow{2}{*}{} & \multicolumn{2}{|c|}{ Pain Location } \\
\cline { 2 - 7 } & \multicolumn{2}{|c}{ Knee } & \multicolumn{2}{c|}{ Leg } & \multicolumn{2}{c|}{ Foot/Ankle } \\
\cline { 2 - 7 } & $\mathrm{R}$ & $\mathrm{p}$-value & $\mathrm{R}$ & $\mathrm{p}$-value & $\mathrm{R}$ & $\mathrm{p}$-value \\
\hline FW & -0.056 & 0.797 & -0.066 & 0.759 & 0.105 & 0.624 \\
\hline FL sit & $\mathbf{- 0 . 3 5 5}$ & $\mathbf{0 . 0 8 9}$ & $\mathbf{- 0 . 3 6 5}$ & $\mathbf{0 . 0 7 9}$ & -0.192 & 0.368 \\
\hline FL stand & -0.210 & 0.325 & -0.227 & 0.286 & -0.022 & 0.919 \\
\hline TFL sit & -0.135 & 0.531 & -0.093 & 0.664 & 0.100 & 0.641 \\
\hline TFL stand & $\mathbf{- 0 . 3 4 6}$ & $\mathbf{0 . 0 9 7}$ & $-\mathbf{0 . 3 5 1}$ & $\mathbf{0 . 0 9 3}$ & -0.100 & 0.643 \\
\hline FH sit & -0.340 & 0.104 & -0.089 & 0.680 & -0.124 & 0.563 \\
\hline FH stand & $\mathbf{- 0 . 4 2 9}$ & $\mathbf{0 . 0 3 7 *}$ & -0.224 & 0.293 & -0.181 & 0.396 \\
\hline AHI sit & -0.225 & 0.292 & -0.072 & 0.737 & -0.159 & 0.458 \\
\hline AHI stand & $\mathbf{- 0 . 4 4 9}$ & $\mathbf{0 . 0 2 8 *}$ & -0.323 & 0.124 & -0.004 & 0.984 \\
\hline AD & -0.135 & 0.528 & -0.141 & 0.512 & -0.139 & 0.516 \\
\hline ARI & -0.022 & 0.919 & 0.114 & 0.597 & $\mathbf{0 . 3 7 1}$ & $\mathbf{0 . 0 7 4}$ \\
\hline AI & 0.041 & 0.847 & 0.006 & 0.977 & -0.064 & 0.767 \\
\hline & & & & & & \\
\hline & & & & & & \\
\hline
\end{tabular}


Table 8: Correlations for Lower Extremity Asymmetry at the low back, hip, and thig

\begin{tabular}{|c|c|c|c|c|c|c|}
\hline \multirow{2}{*}{} & \multicolumn{4}{|c|}{ Pain Location } \\
\cline { 2 - 7 } & \multicolumn{2}{|c|}{ Low Back } & \multicolumn{2}{c|}{ Hip } & \multicolumn{2}{c|}{ Thigh } \\
\cline { 2 - 7 } & $\mathrm{R}$ & $\mathrm{p}$-value & $\mathrm{R}$ & $\mathrm{p}$-value & $\mathrm{R}$ & $\mathrm{p}$-value \\
\hline RFA & 0.144 & 0.503 & 0.119 & 0.58 & 0.099 & 0.647 \\
\hline Leg length & 0.115 & 0.593 & 0.226 & 0.288 & -0.061 & 0.777 \\
\hline ASIS-PSIS (cm) & 0.202 & 0.344 & $\mathbf{0 . 3 8 3}$ & $\mathbf{0 . 0 6 5}$ & 0.262 & 0.217 \\
\hline ASIS-PSIS (deg) & $\mathbf{0 . 3 6 8}$ & $\mathbf{0 . 0 7 6}$ & 0.208 & 0.330 & $\mathbf{0 . 3 5 1}$ & $\mathbf{0 . 0 9 3}$ \\
\hline Knee Angle diff(deg) & 0.119 & 0.579 & 0.064 & 0.768 & 0.315 & 0.134 \\
\hline ABD Avg pk torque & 0.233 & 0.273 & -0.014 & 0.947 & -0.0073 & 0.736 \\
\hline ADD Avg pk torque & -0.253 & 0.232 & -0.237 & 0.266 & $\mathbf{- 0 . 4 1 5}$ & $\mathbf{0 . 0 4 4}$ \\
\hline
\end{tabular}

Table 9: Correlations for Lower Extremity Asymmetry at the knee, leg, and foot/ankle.

\begin{tabular}{|c|c|c|c|c|c|c|}
\hline & \multicolumn{6}{|c|}{ Pain Location } \\
\hline & \multicolumn{2}{|c|}{ Knee } & \multicolumn{2}{|c|}{ Leg } & \multicolumn{2}{|c|}{ Foot/Ankle } \\
\hline & $\mathrm{R}$ & p-value & $\mathrm{R}$ & p-value & $\mathrm{R}$ & p-value \\
\hline RFA & 0.234 & 0.272 & 0.174 & 0.415 & 0.202 & 0.344 \\
\hline Leg length & -0.020 & 0.928 & -0.012 & 0.956 & 0.267 & 0.207 \\
\hline ASIS-PSIS $(\mathrm{cm})$ & 0.079 & 0.714 & 0.237 & 0.264 & 0.272 & 0.198 \\
\hline ASIS-PSIS (deg) & 0.314 & 0.135 & 0.067 & 0.757 & -0.029 & 0.892 \\
\hline Knee Angle diff (deg) & 0.349 & 0.095 & 0.454 & $0.026^{*}$ & 0.161 & 0.453 \\
\hline ABD Avg pk torque & -0.251 & 0.237 & -0.168 & 0.432 & 0.018 & 0.932 \\
\hline ADD Avg pk torque & -0.404 & $0.050 *$ & -0.41 & $0.046^{*}$ & -0.388 & 0.061 \\
\hline
\end{tabular}




\section{Comparison of Ancillary variables between groups}

A number of variables were collected that were not directly related to the specific aims of the study, but rather, their purpose was to provide insight into our results and to help explain any differences that we may have found in the study. These variables included: number of miscarriages, history of nursing, currently nursing, postpartum depression, time since delivery, physical activity level prior to pregnancy, during pregnancy, and currently active (Table 10).

No significant differences existed between the groups for the number of miscarriages $(p=0.446)$. The time since delivery did not differ between the groups $(p=0.128)$. Six of the no pain postpartum women, and seven of the pain postpartum women breast fed after parturition. At the time of testing, four postpartum no pain women reported currently breastfeeding, while only three postpartum pain women were still nursing. No difference existed between the postpartum groups and postpartum depression $(\mathrm{p}=0.929)$.

No significance was found between the postpartum groups and history of breastfeeding $(p=0.893)$ and currently breast feeding $(p=0.486)$. A chi-square analysis of breast feeding after parturition and pain revealed no significance at the low back $(\mathrm{p}=0.682)$, no significance at the hip $(\mathrm{p}=0.825)$, and no significance at the thigh $(\mathrm{p}=0.567)$. Pain at the knee, leg, and foot/ankle with breast feeding after parturition had no significant difference between women who reported pain and who did not report pain $(\mathrm{p}=0.347, \mathrm{p}=0.567, \mathrm{p}=0.937)$. Current breastfeeding and pain revealed no significance at the low back $(p=0.906)$, hip $(p=0.252)$, thigh $(p=0.218)$, knee $(p=0.787), \operatorname{leg}(p=0.218)$, and the foot/ankle $(p=0.452)$.

Physical activity levels were not different between the three subject groups $(\mathrm{p}=0.565)$. The postpartum groups did not significantly differ in physical activity level during pregnancy 
$(p=0.929)$. A $p$-value of 0.156 showed no significance in current activity level between the postpartum groups.

Table 10: Ancillary Data

\begin{tabular}{|c|c|c|c|}
\hline & Postpartum Pain & Postpartum No Pain & Control \\
\hline \# Miscarriages & $0.22 \pm 0.44$ & $0.13 \pm 0.35$ & 0 \\
\hline $\begin{array}{c}\text { Time since delivery } \\
\text { (months) }\end{array}$ & $11.78 \pm 6.69$ & $7.88 \pm 1.51$ & N/A \\
\hline History of Nursing & $77.8 \%$ & $75 \%$ & N/A \\
\hline Currently Nursing & $33.3 \%$ & $50 \%$ & N/A \\
\hline Postpartum Depression & $11.1 \%$ & $12.5 \%$ & N/A \\
\hline $\begin{array}{c}\text { Physically Active prior } \\
\text { to pregnancy }\end{array}$ & $88.9 \%$ & $100 \%$ & $85.7 \%$ \\
\hline $\begin{array}{c}\text { Physically Active } \\
\text { During Pregnancy }\end{array}$ & $88.9 \%$ & $87.5 \%$ & N/A \\
\hline $\begin{array}{c}\text { Physically Active } \\
\text { Postpartum }\end{array}$ & $77.8 \%$ & $100 \%$ & N/A \\
\hline
\end{tabular}


Table 11: Percent of Pain reported at the 6 location.

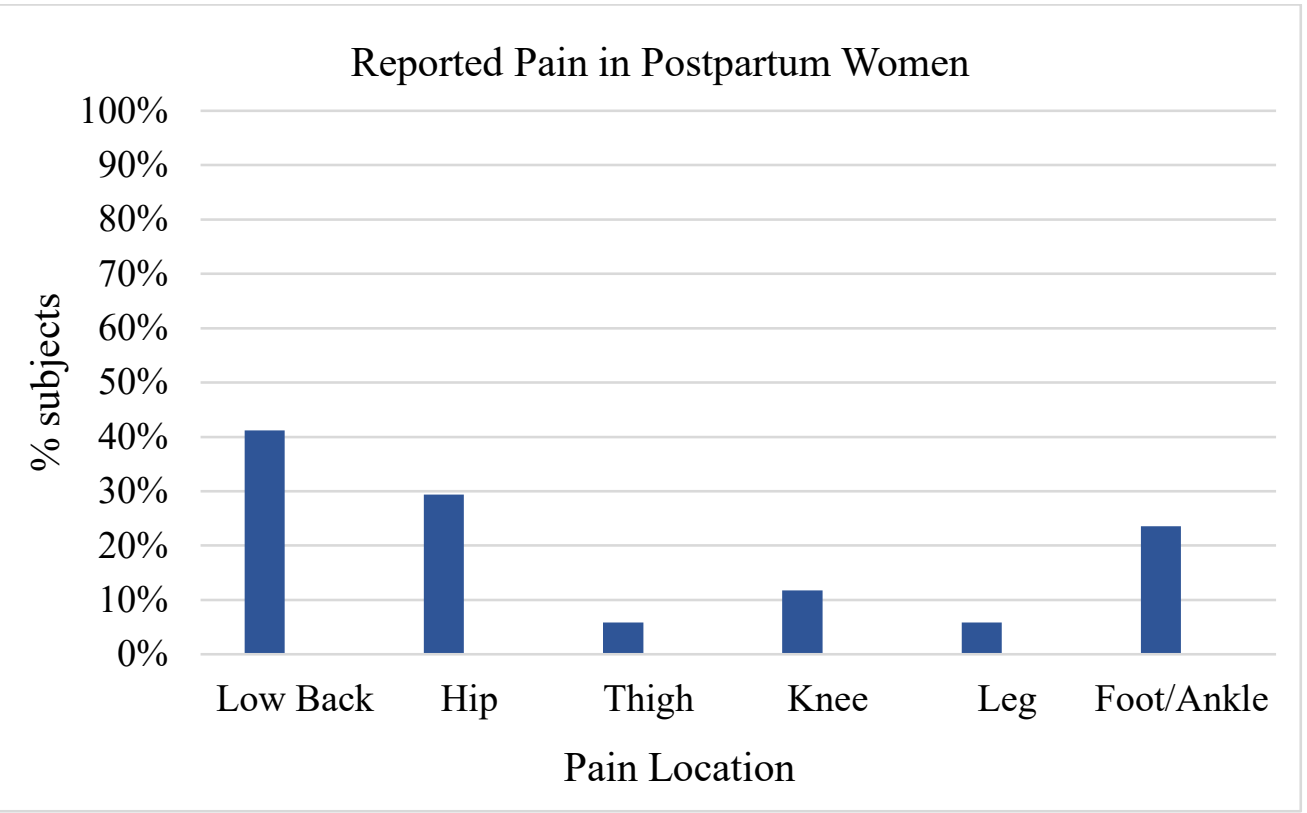




\section{Chapter 5: Discussion}

The purpose of this study was to assess malalignment in postpartum women, as well as to determine if the magnitude of an asymmetry was related to the magnitude of self-reported pain, particularly at the lumbar spine, posterior pelvis, and foot. Many changes to alignment occur during pregnancy, such as increased arch drop (3), foot length (3), foot width (3), foot volume (30), and decreased arch rigidity (23). Additionally, others have investigated asymmetries to pelvic obliquity, iliac crest heights, and rearfoot angle in pregnant and healthy controls, but their sample sizes were small $(15,29)$. Although many variables were investigated as to their role in pain during pregnancy, not many have been studied in the postpartum period.

Numerous researchers have examined pain levels and location during pregnancy $(4,7$, $15,22,29)$. Several studies reported on these pains in the postpartum period $(6,8,21)$. However, few have examined the contribution of musculoskeletal measures in post-partum pain $(11,16)$.

Although some researchers have reported on pain following parturition $(11,16,29)$, a thorough investigation of post-partum pain as well as a description of post-partum asymmetry has not been reported in the literature. Therefore, it was important to investigate the contribution of lower extremity asymmetry and the relationship of various measures of asymmetry to pain.

The first Specific Aim of this study was to quantify foot, lower extremity, and pelvic asymmetries in women with low back, pelvic, leg and foot pain postpartum and compare to a control group of nulligravida women and a postpartum group who do not report lingering pain following pregnancy. In addition to various measures of lower extremity asymmetry, we also assessed Beighton's test and the Sit and Reach test to determine if laxity in general, or lumbar/hamstring flexibility, in particular, were different between women in pain and not in pain post-partum. The second Specific Aim of this study was to examine the relationship between the 
biomechanical measurements of alignment and strength, and self-reported measures of foot, lower extremity, pelvic, and lumbar spine pain in all subjects.

Almost $42 \%$ of postpartum women experienced low back pain, nearly $30 \%$ reported hip/buttocks pain, and only about $6 \%$ had thigh pain (Table 11). Previous literature reported about $50 \%$ of women experience back pain during pregnancy (2), around $30 \%$ of those women conveyed continued back pain at six months postpartum (6), so our findings corroborate those of Olsson et al. (6) regarding back pain postpartum. According to Albert et al (7), of the $20 \%$ of women with pelvic pain during pregnancy, about $25 \%$ continue experiencing pain postpartum. In this study, nearly $30 \%$ of the postpartum women reported hip and buttocks pain.

This study revealed about $12 \%$ of postpartum women indicated knee pain, approximately $6 \%$ leg pain, and $24 \%$ experienced foot and ankle pain. Vullo et al (8) reported $42 \%$ of recently postpartum women were experiencing general foot pain, but no significant leg or knee pain. Although some of our pain results do not agree with those of Vullo et al. (8), it may due to the method in which it was obtained; we used a validated visual analog scale (46), while Vullo (8) used a non-validated questionnaire.

\section{$\underline{\text { Specific Aim } 1}$}

We hypothesized that the postpartum pain group would have increased asymmetries in arch drop, arch index, arch height index, subtalar joint angle, foot length, foot width, leg length, pelvic obliquity, dynamic knee valgus, and hip strength compared to the control group of nulligravida women and the postpartum women not in pain. Our findings do not support that hypothesis because we found no significant differences in any of the variables when compared between the postpartum pain, postpartum no pain, and control groups. 
However, we discovered a trend of increased foot width in the postpartum no pain group compared to the postpartum pain group $(\mathrm{p}=0.099)$, and a power analysis revealed a sample size of 54 would be needed to determine statistical significance between the groups. Harrison (29) reported no significant change in foot width during pregnancy, while Ponnapula and Boberg (13) reported a significant increase in foot width during and after pregnancy. Foot width may remain increased in postpartum period, but it is necessary to obtain a larger sample size to find significance in this variable.

Casto (15) compared pregnant women who reported pain in their third trimester and pregnant women who did not report pain. She noted a trend of higher arch rigidity index in pregnant women in pain, but that trend did not hold true for postpartum women in this study $(\mathrm{p}=0.837)$. Casto speculated that the higher ARI may have been caused from swelling during late pregnancy, which usually resolves soon after parturition.

Although, a significant increase in foot length was previously reported in other studies as persisting postpartum $(11,29)$, no significant change to foot length was discovered when seated or standing between postpartum pain, postpartum no pain, and the control groups. As this study was cross-sectional and not longitudinal, we were not able to assess if the post-partum women in this study experienced a greater foot length following pregnancy.

The average peak abduction torque asymmetry was near significance $(\mathrm{p}=0.058)$ between the postpartum no pain group and the control. Although there was no difference between the postpartum groups. On the contrary, Arab and Nourbakhsh (17) reported subjects with low back pain had significantly weaker hip abductor muscles. This may be from error of the subject, since there was no familiarization period. This test using the dynamometer only takes a few minutes for each hip, so multiple trials on each side could prove more accurate results. 
Additionally, we hypothesized that postpartum women in pain would have decreased flexibility and higher Beighton's scores. We hypothesized decreased flexibility because it is well known decreased lumbar and hamstring flexibility can be related to low back pain. We hypothesized Beighton's scores would be higher because Relaxin increases the flexibility of the ligaments (9), and several studies examining pregnancy reported decreased low back and increased pelvic pain with greater circulating serum levels of Relaxin in pregnant women (16, 25). However, our data showed no difference in either flexibility or hypermobility between all three groups. Although our results indicated no significant difference between groups, four postpartum women had hypermobility or a Beighton's score greater than five, and several other post-partum women were nearing hypermobility. The two with the highest Beighton scores were in the pain group. On the contrary, Harrison (29), who performed a longitudinal study of the first, second, and third trimesters as well as one month post-partum, reported Beighton scores were the lowest during the post-partum period. Because Harrison (29) and this study had small sample sizes, more research is necessary to further investigate whether relaxin continues to play a role in the postpartum period.

Despite looking at many asymmetry variables and comparing them between all three subject groups, we found no significance. We did not assess the postpartum women's pain during or soon after parturition, so areas of pain during those times were unknown. We did not ask the subjects whether they were using any device likes orthotics for any pain that may have occurred. Orthotics or braces could affect many of the foot variables like arch rigidity and arch height. In addition to the orthotics, we did not ask what types of shoes they were regularly that may be more supportive for some. We did not assess the amount of time spent walking or standing daily 
that could also affect our lower extremity asymmetry measurements and the amount of pain the participant reports. Most of the measurements are asymmetry values, and not absolute values.

\section{$\underline{\text { Specific Aim } 2}$}

We hypothesized that greater pelvic and lower extremity asymmetry would be positively correlated with foot, leg, pelvic, and lumbar spine pain in the study participants. Our hypothesis was both correct and incorrect depending on the variable. It is important to note this was the first study to thoroughly investigate all of the above variables in postpartum women, and to analyze whether those variables were correlated to pain. A previous study that was completed in our biomechanics lab briefly examined postpartum women, but the main focus was a longitudinal examination of pain and the development of asymmetry over the course of a pregnancy and into the early post-partum period (29). Harrison (29) reported a few relationships between asymmetry and pain in that study that we did not determine in the current study, namely: arch drop asymmetry was negatively correlated to thigh, knee, leg, and foot/ankle pain $(p=0.02, p=0.02$, $\mathrm{p}=0.04, \mathrm{p}=0.01)$ and arch index asymmetry was trending towards a significantly positive correlation to leg pain $(\mathrm{p}=0.09)$. Additionally, arch rigidity index trended toward significance with a negative correlation to thigh and foot/ankle pain $(\mathrm{p}=0.09, \mathrm{p}=0.07)$. The arch drop and arch rigidity index correlations revealed more flexible arches were associated with more pain (29) However, other asymmetries in the variables were not found significant or not assessed until this current study.

Foot length asymmetry while seated, which is non-weightbearing, was negatively correlated to thigh pain, indicating that less foot length asymmetry meant more thigh pain. On the contrary, Menz et al. (50) found that pronated foot function during walking was significantly correlated to low back pain, but asymmetry of the foot posture and structure was not related to low back pain. 
Foot length asymmetry when seated was trending towards a significant relationship with low back, knee, and leg pain, so decreased foot length asymmetry was related to increased pain in low back, knee and leg. A negative trend exists for seated foot height asymmetry to pain at the low back and hip. Standing foot height asymmetry and hip pain were negatively correlated, meaning greater foot height asymmetry means less pain at the hip. Foot height asymmetry standing was significantly negatively correlated to knee pain. Greater foot height asymmetry was indicative of lesser knee pain. Seated arch height index asymmetry and low back and thigh pain had a significantly negative relationship. The greater the arch height index asymmetry seated relates to less low back and thigh pain. Significantly negatively correlated was standing arch height index asymmetry and hip, thigh, and knee pain, so increased arch height index asymmetry standing indicated decreased hip, thigh and knee pain. With contrasting results from previous studies, more research is necessary to investigate the relationship between lower extremity asymmetry and pain.

A positive trend was shown between pelvic torsion asymmetry and hip pain. Harrison (29) reported some contrasting findings to pelvic asymmetry because she found greater pelvic obliquity in controls and decreased pain in the foot/ankle, with no significance established for low back pain. More research is needed to further examine pelvic asymmetry and its relation to pain.

Also, increased knee angle asymmetry contributed to increased pain of the leg. A negative relationship exists between the peak average hip adduction torque asymmetry and thigh, knee, and leg pain. Rowe (39) discovered people with knee pain have weak hip musculature. Hip flexors and abductors were significantly weaker while the hip adductors were stronger in the injured lower extremity of runners (41). 


\section{Ancillary variables:}

During breastfeeding, two hormones are released: Prolactin and Oxytocin. Oxytocin is the main hormone responsible for uterine contractions during pregnancy and lactation. In addition to the contractions and lactation, Oxytocin is known for modulating pain and stress (51). In this study, we compared the postpartum groups to past and current breastfeeding, and found no significant difference. No significant relationship was found between past and current breasting when correlated to pain.

In this study we investigated physical activity levels at three different time points between the groups. It is well known that tight muscles or inactivity may have an effect on pain levels. We discovered no significant difference between our groups and physical activity prior, during, or after pregnancy. Abdominal muscles are weakened during pregnancy which may be related to poor posture and low back pain (4). Based on our study's findings, it may be beneficial to examine core muscular strength, and physical activity level.

\section{$\underline{\text { Limitations }}$}

In this study, there were numerous limitations. Firstly, we used healthy, nulliparous controls as a baseline to represent the pre-pregnancy data for the postpartum women. The control subjects were significantly younger than the postpartum pain group $(\mathrm{p}=0.015)$, however the age did not significantly differ between the postpartum pain and the postpartum no pain groups. Our postpartum ages ranged from 26-37 years old, and because of this range it might wash out some findings since younger women report more pain during pregnancy (52). Due to a time constraint, no familiarization was given for the muscular strength test for the hip abductors and adductors using the Biodex isokinetic dynamometer, which may have affected the validity of the maximum 
peak torque. We had low statistical power for multiple variables because of the small sample size.

Some of the postpartum women had BMIs of overweight or obese and still retained the increased adipose tissue surrounding their abdomens that was associated with their pregnancies. The arms of the palpation meter did not extend. For this reason, using the palpating meter for pelvic measurements on postpartum women may not have been as valid as in individuals in the normal BMI range.

Pain reported by the subjects was subjective and could not be directly measured. Thus, we used a self-reported pain questionnaire. Even though it was a validated questionnaire, individuals may have different levels of reported pain because of the varying degree of pain tolerance that exists.

The time of day each subject was tested greatly varied. Some women had very active jobs, and were on their feet all day, which may have affected measurements specifically of the foot, and the Sit and Reach test. Secondly, our study took an hour to complete all the necessary assessments. With that time restriction, it was not possible to take multiple measurements to reduce the possibility for human error.

\section{$\underline{\text { Future Studies }}$}

A longitudinal study to examine the development of asymmetries and pain was not possible at this time. Future research should look at measurements pre-pregnancy, during pregnancy, and postpartum for more accurate results, so a nulliparous control group would not be necessary. Nulliparous women have asymmetries, so pregnancy may be augmenting preexisting asymmetries. Testing the subjects at similar times of day would be ideal, as gravity and activity level can affect certain variables, so morning would be an optimal time. Since abdominals 
muscles are weakened during pregnancy, future studies should assess core abdominal muscles as a possible factor contributing to low back pain. A spine functional index (SFI) questionnaire should be given to assess whether pain impacts function, and to help control for subjective aspects of pain. In addition to the SFI, we should add an objective measurement to quantify pain using a dolorimeter.

Casto (15) assessed foot volume during pregnancy and indicated it may be related to swelling during pregnancy, so research should examine foot volume to assess whether swelling is still a factor postpartum. Swelling of the feet could affect range of motion of the ankle, so that is another variable that could be measured. Although previous studies found correlations between pain and arch index during pregnancy, our study on postpartum women did not. This could mean that arch index is not the variable to examine. Wafai et al. (53) found that higher asymmetry of foot pressure was significantly different in certain pathological populations experiencing foot pain, and Menz (50) found pronated plantar function was related to low back pain. Measurements of plantar pressure may be what needs to be assessed and compared to pain.

\section{Conclusion}

This study revealed, several relationships exist between pelvic and lower extremity asymmetry and pain in postpartum women. We identified multiple areas of asymmetry, at the hip, knee, and especially in the foot that are correlated to pain. This information may be helpful to clinicians and their treatment of asymmetries during pregnancy to prevent pain during the postpartum period. With the high prevalence of pain that still remains postpartum, further research is necessary. A larger sample size is needed to validate the trends found in this study regarding asymmetry and pain. 


\section{References}

1. Close C, Sinclair M, Liddle D, McCullough B, Hughes C. Women's experience of low back and or pelvic pain (LBPP) during pregnancy. Midwifery. 2016;37:1-8.

2. Ostgaard H, Andersson G, Karlsson K. Prevalence of back pain in pregnancy. Spine. 1991;16(5):549-52.

3. Chiou W, Chiu H, Chao A, Wang M, Chen Y. The influence of body mass on foot dimensions during pregnancy. Applied Ergonomics: Part A. 2015;46:212-7.

4. Franklin M, Conner-Kerr T. An analysis of posture and back pain in the first and third trimesters of pregnancy. The Journal of orthopaedic and sports physical therapy. 1998;28(3):133-8.

5. $\quad$ Fitzgerald C, Segal N. Musculoskeletal Health in Pregnancy and Postpartum. 2015.

6. Olsson C, Nilsson-Wikmar L, Grooten W. Determinants for lumbopelvic pain 6 months postpartum. Disabil Rehabil. 2012;34(5):416-22.

7. Albert H, Godskesen M, Korsholm L, Westergaard J. Risk factors in developing pregnancy-related pelvic girdle pain. Acta Obstetricia et Gynecologica Scandinavica. 2006;85(5):539-44.

8. Vullo V, JK R, Hurvitz E. Hip, knee, and foot pain during pregnancy and the postpartum period. The Journal of family practice. 1996;43(1):63-8.

9. Heckman J, Sassard R. Musculoskeletal considerations in pregnancy. The Journal of bone and joint surgery. 1994;76(11):1720-30.

10. Calguneri M, Bird H, Wright V. Changes in joint laxity occurring during pregnancy. Annals of Rheumatic Diseases. 1982;41(2):126-8.

11. Segal N, Boyer E, Teran-Yengle P, Glass N, Hillstrom H, Yack H. Pregnancy leads to lasting changes in foot structure. American journal of physical medicine \& rehabilitation. 2013;92(3):232-40.

12. Dunn J, Dunn C, Habbu R, Bohay D, Anderson J. Effect of Pregnancy and Obesity on Arch of Foot. Orthopaedic Surgery. 2012;4(2):101-4.

13. Ponnapula P, Boberg J. Lower Extremity Changes Experienced During Pregnancy. The Journal of Foot and Ankle Surgery. 2010;49(5):452-8.

14. Damen L, Buyruk H, Guler-Uysal F, Lotgering F, Snijders C, Stam H. Pelvic pain during pregnancy is associated with asymmetric laxity of the sacroiliac joints. In: 2001.

15. Casto E. The Effect of Lower Extremity Asymmetries on Low Back and Lower Extremity Pain with Pregnancy. Morgantown, WV: West Virginia University; 2016. 69 p.

16. Lindgren A, Kristiansson P. Finger joint laxity, number of previous pregnancies and pregnancy induced back pain in a cohort study. BMC Pregnancy and Childbirth. 2014;14(1):1-7.

17. Arab A, Nourbakhsh M. The relationship between hip abductor muscle strength and iliotibial band tightness in individuals with low back pain. Chiropractic and Osteopathy. 2010;18(1).

18. Borg-Stein J, Fogelman D, Ackerman K. Exercise, Sports Participation, and Musculoskeletal Disorders of Pregnancy and Postpartum. Seminars in Neurology. 2011;31:413-22. 
19. Al-Eisa E, Egan D, Wassersug R. Fluctuating asymmetry and low back pain. Evolution and Human Behavior. 2004;25(1):31-7.

20. Damen L, Buyruk H, Guler-Uysal F, Lotgering F, Snijders C, Stam H. The prognostic value of asymmetric laxity of the sacroiliac joints in pregnancy-related pelvic pain. Spine. 2002;27(24):2820-4.

21. Bergstrom C, Persson M, Mogren I. Pregnancy-related low back pain and pelvic girdle pain approximately 14 months after pregnancy - pain status, self-rated health and family situation. BMC Pregnancy Childbirth. 2014;14:48.

22. Chang H, Lai $Y$, Jensen $M$ et al. Factors associated with low back pain changes during the third trimester of pregnancy. Journal of Advanced Nursing. 2014;70(5):1054-64.

23. Mogren I. BMI, pain and hyper-mobility are determinants of long-term outcome for women with low back pain and pelvic pain during pregnancy | SpringerLink. 2006.

24. Mahishale A, Borkar S. Determining the prevalence of patterns of pregnancy-induced pelvic pain and low back pain in urban and rural populations: A cross-sectional study. Journal of the Scientific Society. 2016;43(2):70-4.

25. MacLennon A, Green R, Nicolson R, Bath M. SERUM RELAXIN AND PELVIC PAIN OF PREGNANCY. The Lancet. 1986;328(8501):243-5.

26. Dragoo J, Lee RS, Benhaim P, Finerman GAM, Hame SL. Relaxin Receptors in the Human Female Anterior Cruciate Ligament. The American Journal of Sports Medicine. 2003;31(4):577-84.

27. Goldsmith L, Weiss G, Steinetz B. Relaxin and its role in pregnancy. Endocrinol Metab Clin North Am. 1995;24:171-86.

28. Conrad KP. Maternal vasodilation in pregnancy: the emerging role of relaxin. $\mathrm{Am} J$ Physiol Regul Integr Comp Physiol. 2011;301(2):R267-75.

29. Harrison K, Mancinelli C, Thomas K, Meszaros P, McCrory J. The Relationship Between Lower Extremity Alignment and Low Back, Hip, and Foot Pain During Pregnancy. Journal of Women's Health Physical Therapy. 2016;40(3):139-46.

30. Alvarez R, Stokes IA, Asprinio DE, Trevino S, Braun T. Dimensional changes of the feet in pregnancy. J Bone Joint Surg Am. 1988;70(2):271-4.

31. Buchanan K, Davis I. The relationship between forefoot, midfoot, and rearfoot static alignment in pain-free individuals. The Journal of orthopaedic and sports physical therapy. 2005;35(9):559-66.

32. Nyska M, Sofer D, Porat A, Howard C, Levi A, Meizner I. Planter foot pressures in pregnant women. Israel Journal of Medical Sciences. 1997;33(2):139-46.

33. Ritchie JR. Orthopedic Considerations During Pregnancy. Clinical Obstetrics and Gynecology. 2003;46(2):456-66.

34. Fann A. The prevalence of postural asymmetry in people with and without chronic low back pain. Archives of Physical Medicine and Rehabilitation. 2002;83(12):1736-8.

35. Dumas GA, Reid JG, Wolfe LA, Griffin MP, McGrath MJ. Exercise, posture, and back pain during pregnancy: Part 2. Exercise and back pain - ScienceDirect. Clinical Biomechanics. 1995;10(2):104-9.

36. Dumas GA, Reid JG, Wolfe LA, Griffin MP, McGrath MJ. Exercise, posture, and back pain during pregnancy: Part 1. Exercise and posture - ScienceDirect. Clinical Biomechanics. 1995;10(2):98-103. 
37. Unsgaard-Tøndel M, Vasseljen O, Woodhouse A, Mørkved S. Exercises for Women with Persistent Pelvic and Low Back Pain after Pregnancy. In. Glob J Health Sci2016, pp. 107-20.

38. Tseng P, Puthussery S, Pappas Y, Gau M. A systematic review of randomised controlled trials on the effectiveness of exercise programs on Lumbo Pelvic Pain among postnatal women. BMC pregnancy and childbirth. 2015;15:316.

39. Rowe J, Shafer L, Kelley K et al. Hip Strength and Knee Pain in Females. North American Journal of Sports Physical Therapy. 2007;2(3):164-9.

40. Roush JR, Curtis Bay R. PREVALENCE OF ANTERIOR KNEE PAIN IN 18-35 YEAR-OLD FEMALES. Int J Sports Phys Ther. 2012;7(4):396-401.

41. Niemuth P, Johnson RJ, Myers M, Thieman T. Hip Muscle Weakness and Overuse Injuries in Recreational Runners. Clinical Journal of Sport Medicine. 2005;15(1):14-21.

42. Sendur O, Gurer G, Yildirim T, Ozturk E, Aydeniz A. Relationship of Q angle and joint hypermobility and Q angle values in different positions. Clinical Rheumatology. 2006;25(3):304-8.

43. Nguyen A-D, Boling M, Levine B, Shultz S. Relationships Between Lower Extremity Alignment and the Quadriceps Angle. In. Clinical Journal of Sport Medicine2009, p 201206.

44. Hollman JH, Ginos BE, Kozuchowski J, Vaughn AS, Krause DA, Youdas JW. Relationships between Knee Valgus, Hip-Muscle Strength, and Hip-Muscle Recruitment during a Single-Limb Step-Down. http://dx.doi.org/10.1123/jsr.18.1.104. 2009;18(1):104-17.

45. Gilleard W, Crosbie J, Smith R. Static trunk posture in sitting and standing during pregnancy and early postpartum. 2002.

46. Stuber J, Zech S, Bay R, Qazzaz A, Richter M. Normative data of the Visual Analogue Scale Foot and Ankle (VAS FA) for pathological conditions. Foot Ankle Surg. 2011;17(3):166-72.

47. Cavanagh P, Rodgers M. The arch index: A useful measure from footprints. Journal of Biomechanics. 1987;20(5):547-51.

48. Medicine ACoS. ACSM's Health-Related Physical Fitness Assessment Manual. Fourth ed. 2013, 129 p.

49. Clarke TE, Frederick EC, Hamill CL. The effects of shoe design parameters on rearfoot control in running. Med Sci Sports Exerc. 1983;15(5):376-81.

50. Menz HB, Dufour AB, Riskowski JL, Hillstrom HJ, Hannan MT. Foot posture, foot function and low back pain: the Framingham Foot Study. Journal of Foot \& Ankle Research. 2013;6:1.

51. Goodin BR, Ness TJ, Robbins MT. Oxytocin - A Multifunctional Analgesic for Chronic Deep Tissue Pain. Curr Pharm Des. 2015;21(7):906-13.

52. Wang S, Dezzino P, Maranets I, Berman M, Caldwell-Andrews A, Kain Z. Low Back Pain During Pregnancy: Prevalence, Risk Factors, and Outcomes. Obstetrics \& Gynecology. 2004;104(1):65-70.

53. Wafai L, Zayegh A, Woulfe J, Aziz SM, Begg R. Identification of Foot Pathologies Based on Plantar Pressure Asymmetry. Sensors (Basel). 2015;15(8):20392-408. 


\section{Appendix A}

\section{Only Minimal Risk \\ Consent Information and \\ HIPAA Form}

Principal Investigator

Department

Protocol Number

Study Title

Co-Investigator(s)
McCrory, Jean

MEDICINE - Exercise Physiology

1709779594

The Effect of Lower Extremity Asymmetry on Pain

During the Postpartum Period

Meder, Krista; Mancinelli, Corrie; Phillips, Kristin

\section{Contact Persons}

In the event you experience any side effects or injury related to this research, you should contact Dr. Jean McCrory at (304) 293-0442. (After hours contact: Dr. Jean McCrory at (724) 554-4955). If you have any questions, concerns, or complaints about this research, you can contact Dr. Stephen Alway at (304) 2930772.

For information regarding your rights as a research subject, to discuss problems, concerns, or suggestions related to the research, to obtain information or offer input about the research, contact the Office of Research Integrity and Compliance at (304) 293-7073.

In addition, if you would like to discuss problems, concerns, have suggestions related to research, or would like to offer input about the research, contact the Office of Research Integrity and Compliance at 304-293-7073.

\section{Introduction}

You, , have been asked to participate in this research study, which has been explained to you by This study is being conducted by Dr. Jean McCrory, PhD, Dr. Corrie Mancinelli, PhD, Dr. Kristin Phillips, DPT, and Krista Meder in the Department of Exercise Physiology at West Virginia University. This study is being conducted as part of Krista Meder's thesis requirements for completion of her Master of Science Degree in Exercise Physiology at West Virginia University, under the supervision of Dr. Jean McCrory, PhD.

\section{Purpose(s) of the Study}

The purpose of this study is to learn more information about how pelvic and lower extremity alignment differences or asymmetries are related to pain in postpartum women. WVU expects to enroll 60 subjects (20 postpartum no pain, 20 postpartum pain, and 20 non-pregnant/postpartum). 


\section{Description of Procedures}

This study involves taking measurements of your hips, legs, and feet, answering a questionnaire on pain, and answering a questionnaire about pregnancy. Only participants in the postpartum groups will complete the subject pregnancy questionnaire. It will take approximately one hour to complete all the following procedures including the questionnaires. You do not have to answer all the questions, and you will have the opportunity to see the questionnaire before signing this consent form.

We will ask you to be barefoot to take the most correct measurements of your feet. We will also ask you to wear close fitting shorts and shirt.

We are looking at the evenness of the left and right sides of your body and whether it's related to pain, so you will be given a questionnaire asking about any pain or discomfort you're experiencing.

Height and weight will be measured using a standard scale. To measure the flexibility of the muscles in your back and legs we will have you do a "sit and reach test." To measure you're overall joint flexibility, we will use the "Beighton's test." The Beighton tests hyperextension of the knees and elbows, if you can touch your thumb to your wrist, if your little finger can go beyond 90 degrees, and touching your palms flat onto the floor. We will also test the strength of your hips using a dynamometer called the "Biodex." One leg will be tested at a time, and your leg will be secured to the machine. You'll be working to move your leg from side to side. You will also be instructed to remain upright with your hands lightly resting on the machine. You will be cautioned to not hike your hip up, nor lean forward or to the side.

We will take some measurements on your feet and alignments of your pelvis, knees, and ankles. All measurements are taken on both sides of your body, and the one we measure first will be randomly chosen. As pregnancy can affect foot size even after birth, we will use an anthropometer and sliding calipers which are similar to rulers to take basic measurements of the feet including arches. Next, we will have you step onto an inkpad to get a footprint, the inkpad is designed so no ink will touch your skin. To measure the angle your foot makes with your leg, you will stand shoulder width apart and we will take a picture of the back of your legs. The knee angle will involve standing on box with one leg and stepping down with the other leg. We will record the movement to find the maximum knee angle. Finally, we will use a palpation meter to measure the alignment of your pelvis.

To ensure confidentiality, both your name and face will not appear in any of the pictures and videos taken, so that nothing identifies you as a participant in this study.

\section{Discomforts}

There are no known or expected risks from participating in this study, except for the mild frustration associated with answering the questions.

\section{Alternatives}

You do not have to participate in this study.

Alternatives that could be considered in your case include: Not participating in this study.

\section{Benefits}

You may not receive any direct benefit from this study. The knowledge gained from this study may eventually benefit others. 


\section{Financial Considerations}

There are no special fees for participating in this study. You will be compensated for participating in the form of a gift card.

You will be paid $\$ 20.00$ for the visit. If you withdraw before the end of the study, no additional payments will be made.

\section{Confidentiality}

Any information about you that is obtained as a result of your participation in this research will be kept as confidential as legally possible. Your research records and test results, just like hospital records, may be subpoenaed by court order or may be inspected by the study sponsor or federal regulatory authorities without your additional consent.

Audiotapes or videotapes will be kept locked up and will be destroyed as soon as possible after the research is finished.

In any publications that result from this research, neither your name nor any information from which you might be identified will be published without your consent.

\section{HIPAA}

We know that information about you and your health is private. We are dedicated to protecting the privacy of that information. Because of this promise, we must get your written authorization (permission) before we may use or disclose your protected health information or share it with others for research purposes.

You can decide to sign or not to sign this authorization section. However, if you choose not to sign this authorization, you will not be able to take part in the research study. Whatever choice you make about this research study will not have an effect on your access to medical care.

\section{Persons/Organizations Providing the Information}

Patient/West Virginia University Hospitals

\section{Persons/Organizations Receiving the Information}

- The research site(s) carrying out this study. This includes UHA or UHA Affiliated, WVU, WVU Hospitals. It also includes each site's research staff and medical staff

- $\quad$ The members and staff of any Institutional Review Board (IRB) that oversees this research study.

\section{The Following Information Will Be Used}

We will be using information from questionnaires, and pictures and video of the participant's legs.

\section{The Information is Being Disclosed for the Following Reasons}


- $\quad$ Review of your data for quality assurance purposes

- $\quad$ Publication of study results (without identifying you)

- Other research purposes such as reviewing the safety or effectiveness of the study drug and other products or therapies; conducting performance reviews of the study drug; evaluating other products or therapies for patients; developing a better understanding of disease; improving the design of future clinical trials

\title{
You May Cancel this Authorization at Any Time by Writing to the Principal Investigator
}

\author{
Jean L. McCrory, PhD, \\ 8315 HSC South \\ PO Box 9227 \\ Morgantown, WV 26506-9227; \\ email: jlmccrory@hsc.wvu.edu
}

If you cancel this authorization, any information that was collected already for this study cannot be withdrawn. Once information is disclosed, according to this authorization, the recipient may redisclose it and then the information may no longer be protected by federal regulations.

You have a right to see and make copies of your medical records. You will not be able to see or copy your records related to the study until the sponsor has completed all work related to the study. At that time, you may ask to see the study doctor's files related to your participation in the study and have the study doctor correct any information about you that is wrong.

This authorization will expire at the end of the study unless you cancel it before that time (or has a specific expiration date).

\section{Voluntary Participation}

Participation in this study is voluntary. You are free to withdraw your consent to participate in this study at any time.

Refusal to participate or withdrawal will not affect [your class standing or grades, as appropriate] and will involve no penalty to you. Refusal to participate or withdrawal will not affect your future care, [or your employee status, as appropriate] at West Virginia University.

In the event new information becomes available that may affect your willingness to participate in this study, this information will be given to you so that you can make an informed decision about whether or not to continue your participation.

You have been given the opportunity to ask questions about the research, and you have received answers concerning areas you did not understand.

Upon signing this form, you will receive a copy.

I willingly consent to participate in this research. 


\section{Signatures}

Signature of Subject

Printed Name Date Time

The participant has had the opportunity to have questions addressed. The participant willingly agrees to be in the study.

Signature of Investigator or Co-Investigator

Printed Name Date Time 


\section{Appendix B}

\section{Postpartum Study: Lower Extremity Pain Visual Analogue Scale}

On the following pages is a questionnaire with questions related to lower body problems (e.g. Pain). These include the lower back, hip/buttocks, upper leg, knee, lower leg and foot/ankle. To answer the questions a scale is available in the form of a line. Please mark the appropriate point on the line with a cross, which describes best your personal situation. At the very left side of the line is the most negative value, at the very right the most positive. Please use only marks, do not write text.

This is an example for an answer of the question "How are you today?" as shown:

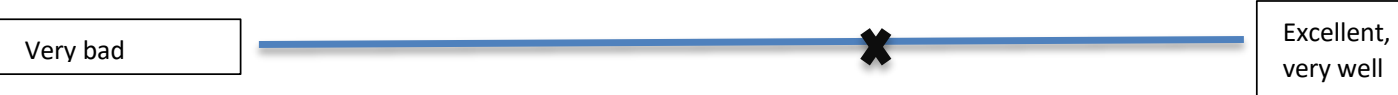

The answer at the cross on the line means in this example that you feel "well", however not "very well".

For any area of pain that applies to you, please indicate with a dot or dots in the red highlighted area of the diagram where exactly you experience pain.

You do not have to answer each question! Answer only the questions which you would like and which you have understood! Please use the field "additions/characteristics/remarks" for suggestions for improvement and/or criticism.

\section{Explanation of some terms:}

Physical rest: This means that you do not do arduous things, i.e. you are reading a paper, lying on the sofa or in a bed, watching television etc.

Physical activity: This means that you are performing physically demanding activities, i.e. arduous garden work, occupational work, sport etc.

Activities of daily life: Personal activities such as getting out of bed, eating, washing yourself, getting dressed, tying your shoes etc. 


\section{RIGHT LOWER BACK}

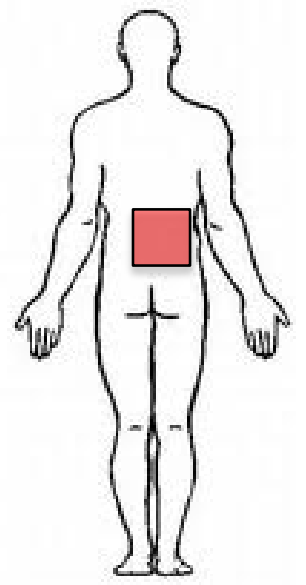

How much does lower back pain affect your gait?

Strong limping

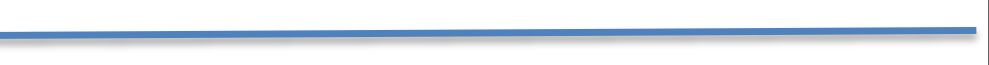

Never, very

rarely

How often do you have lower back pain in physical rest?

Constantly,

always

Never, very rarely

How intense is this back pain in physical rest?

Extreme pain

No pain

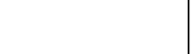

How often do you have lower back pain during physical activity?

Constantly,

Never, very rarely

How strong is this lower back pain during physical activity?

Strong limping

Never, very

rarely

How much do lower back problems affect your daily activities (eg. getting dressed, eating, washing, etc.)?

\section{.}

constant help

No limitation climbing

stairs 


\section{LEFT LOWER BACK}

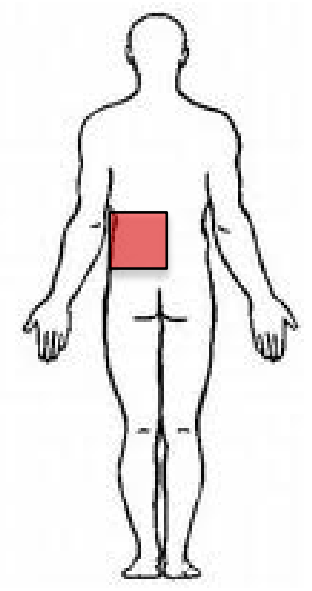

How much does lower back pain affect your gait?

Strong limping

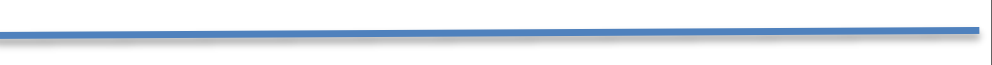

Never, very

rarely

How often do you have lower back pain in physical rest?

Constantly,

always

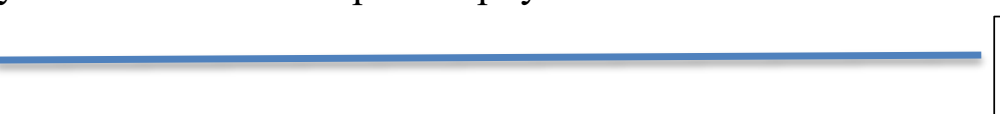

Never, very rarely

How intense is this back pain in physical rest?

Extreme pain

No pain

How often do you have lower back pain during physical activity?

Constantly, always

Never, very rarely

How strong is this lower back pain during physical activity?

Strong limping

Never, very

rarely

How much do lower back problems affect your daily activities (eg. getting dressed, eating, washing, etc.)? 


\section{RIGHT HIP/BUTTOCKS}

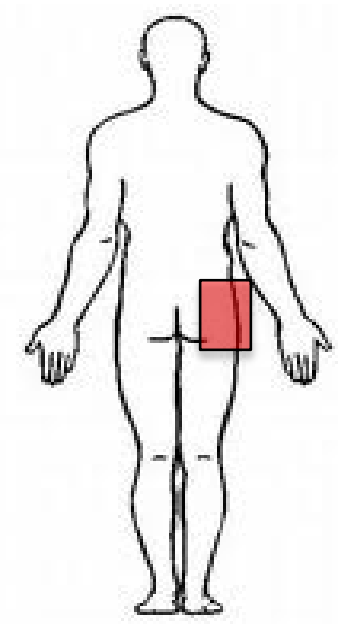

How much does hip/buttocks pain affect your gait?

Strong limping

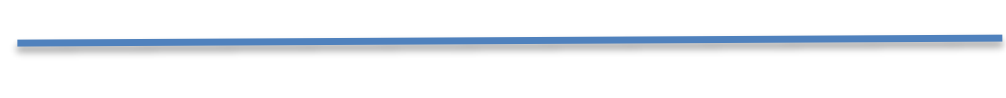

Never, very rarely

How often do you have hip/buttocks pain in physical rest?

\section{Constantly,} always

Never, very rarely

How intense is this hip/buttocks in physical rest?

Extreme pain

No pain

How often do you have hip/buttocks pain during physical activity?

Constantly,

always

How strong is this hip/buttocks pain during physical activity?

Strong limping

How much do hip/buttocks problems affect your daily activities (eg. getting dressed, eating, washing, etc.)?
No limitation

climbing

stairs 


\section{LEFT HIP/BUTTOCKS}

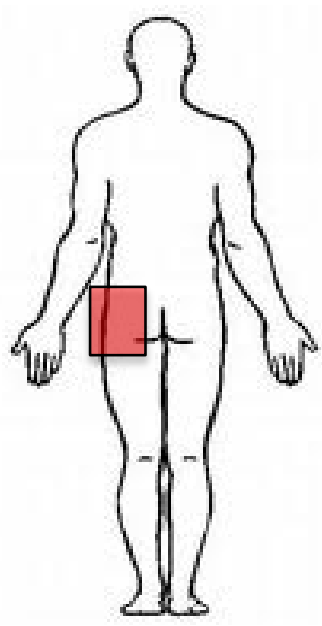

How much does hip/buttocks pain affect your gait?

Strong limping

Never, very rarely

How often do you have hip/buttocks pain in physical rest?

Constantly, always
Never, very rarely

No pain

Never, very rarely

Never, very rarely

How much do hip/buttocks problems affect your daily activities (eg. getting dressed, eating, washing, etc.)?

$$
\begin{aligned}
& \text { Impossible on } \\
& \text { my own, need } \\
& \text { constant heln }
\end{aligned}
$$




\section{RIGHT UPPER LEG}

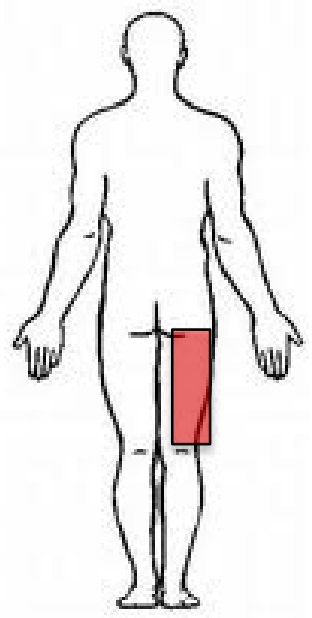

How much does upper leg pain affect your gait?

Strong limping

Never, very

rarely

How often do you have upper leg pain in physical rest?

\begin{tabular}{l}
$\begin{array}{l}\text { Constantly, } \\
\text { always }\end{array}$ \\
\hline
\end{tabular}

Never, very

rarely

How intense is this upper leg in physical rest?

Extreme pain

No pain

How often do you have upper leg pain during physical activity?

Constantly,

always

Never, very

rarely

How strong is this upper leg pain during physical activity?

Strong limping

Never, very rarely

How much do upper leg problems affect your daily activities (eg. getting dressed, eating, washing, etc.)?

Impossible on

my own, need

No limitation

constant help

climbing

stairs 


\section{LEFT UPPER LEG}

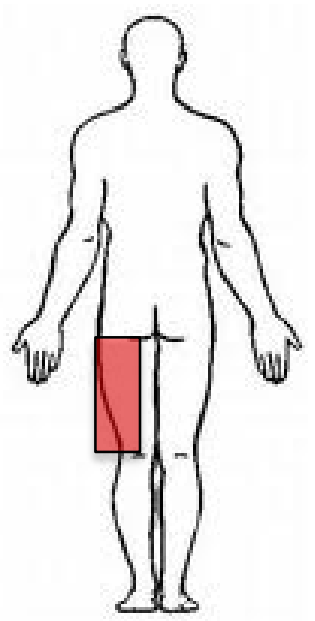

How much does upper leg pain affect your gait?

Strong limping

Never, very

rarely

How often do you have upper leg pain in physical rest?

\begin{tabular}{l}
$\begin{array}{l}\text { Constantly, } \\
\text { always }\end{array}$ \\
\hline
\end{tabular}

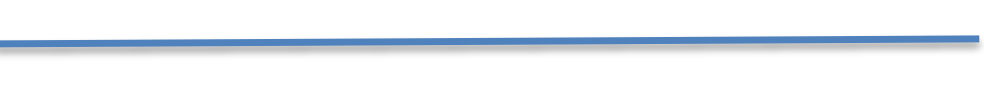

Never, very

rarely

How intense is this upper leg in physical rest?

Extreme pain

No pain

How often do you have upper leg pain during physical activity?

Constantly,

always

Never, very

rarely

How strong is this upper leg pain during physical activity?

Strong limping

Never, very rarely

How much do upper leg problems affect your daily activities (eg. getting dressed, eating, washing, etc.)?

Impossible on

my own, need

No limitation

constant help

climbing

stairs 


\section{RIGHT KNEE}
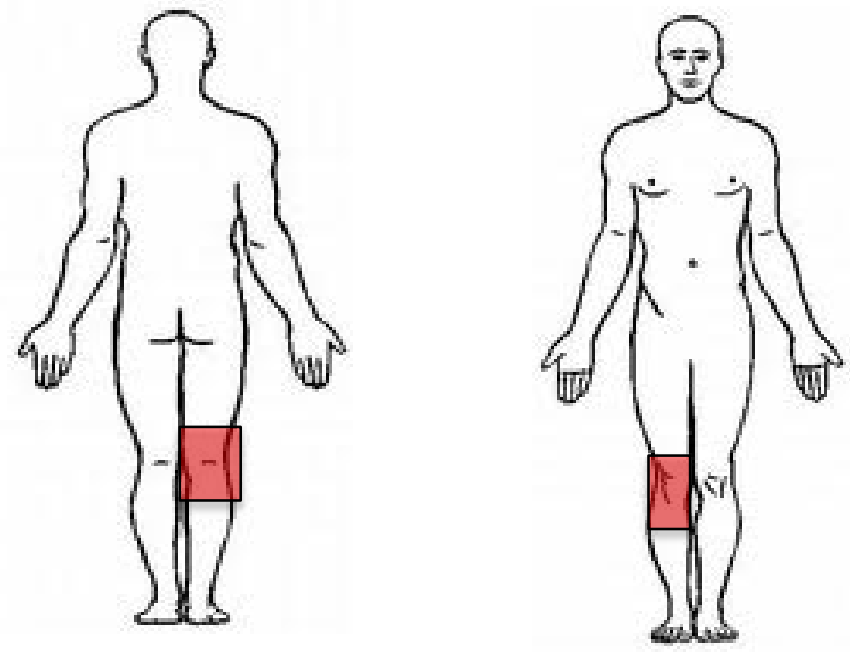

How much does knee pain affect your gait?

Strong limping

How often do you have knee pain in physical rest?

\begin{tabular}{|l|}
\hline $\begin{array}{l}\text { Constantly, } \\
\text { always }\end{array}$ \\
\hline
\end{tabular}

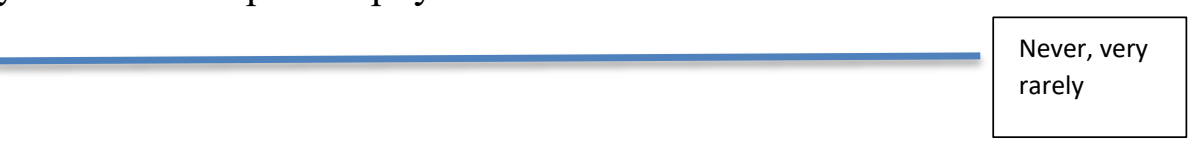

How intense is this knee in physical rest?

\begin{tabular}{|l|}
\hline Extreme pain \\
\hline
\end{tabular}

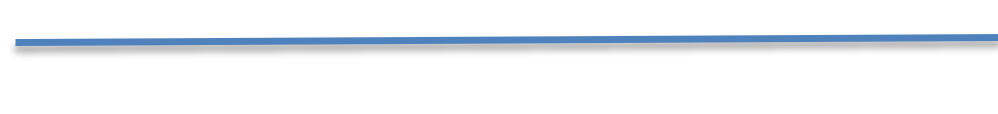

No pain

How often do you have knee pain during physical activity?

Constantly,
always

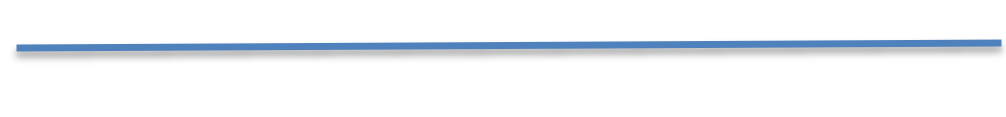

Never, very rarely

How strong is this knee pain during physical activity?

Strong limping

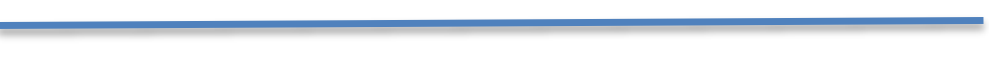

Never, very rarely

How much do knee problems affect your daily activities (eg. getting dressed, eating, washing, etc.)?

Impossible on
my own, need
constant help

\begin{tabular}{ll|} 
No limitation \\
climbing \\
stairs
\end{tabular}




\section{LEFT KNEE}
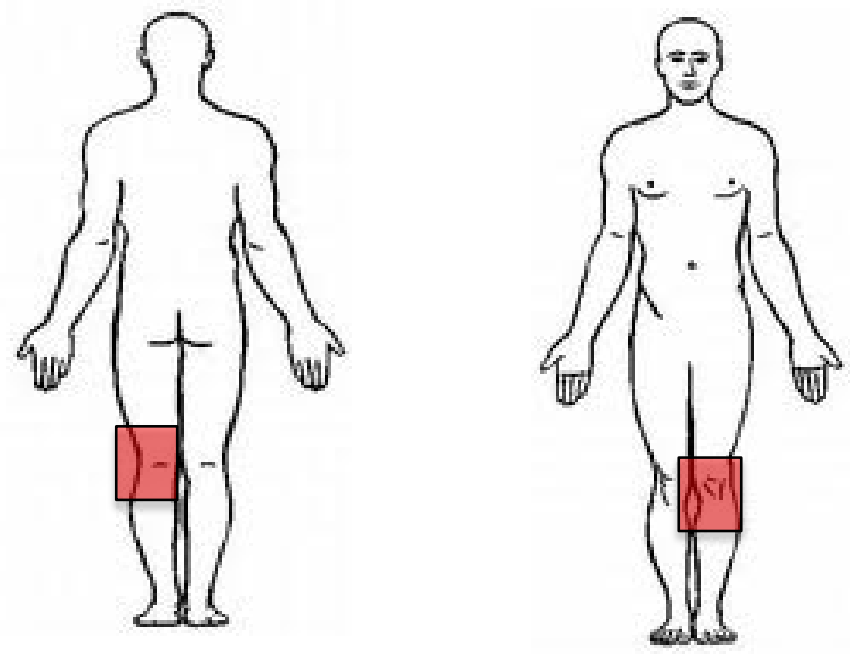

How much does knee pain affect your gait?

Strong limping

Never, very

rarely

How often do you have knee pain in physical rest?

\begin{tabular}{|l|}
\hline $\begin{array}{l}\text { Constantly, } \\
\text { always }\end{array}$ \\
\hline
\end{tabular}

Never, very

rarely

How intense is this knee in physical rest?

Extreme pain

No pain

How often do you have knee pain during physical activity?

Constantly,

always

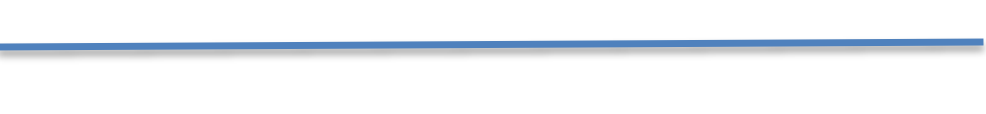

Never, very rarely

How strong is this knee pain during physical activity?

Strong limping

Never, very rarely

How much do knee problems affect your daily activities (eg. getting dressed, eating, washing, etc.)? 


\section{RIGHT LOWER LEG}

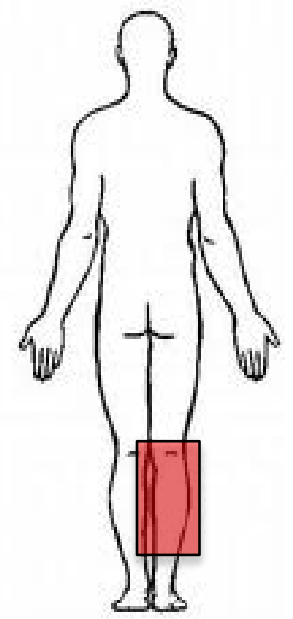

How much does lower leg pain affect your gait?

Strong limping

Never, very

rarely

How often do you have lower leg pain in physical rest?

Constantly,

always

Never, very

rarely

How intense is this lower leg in physical rest?

Extreme pain

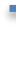

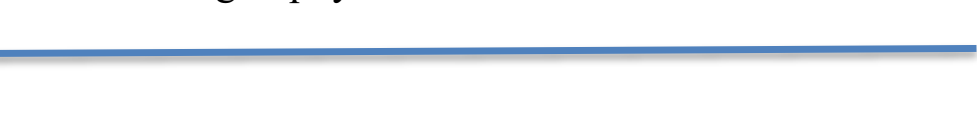

No pain

How often do you have lower leg pain during physical activity?

\begin{tabular}{l|}
\hline $\begin{array}{l}\text { Constantly, } \\
\text { always }\end{array}$ \\
\hline
\end{tabular}

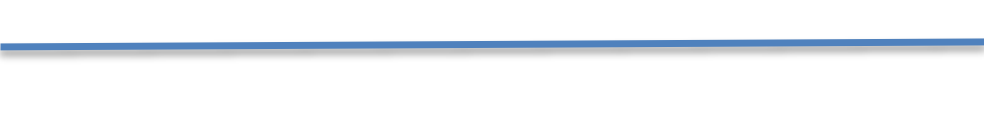

Never, very

rarely

How strong is this lower leg pain during physical activity?

Strong limping
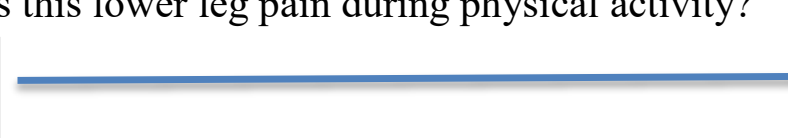

Never, very rarely

How much do lower leg problems affect your daily activities (eg. getting dressed, eating, washing, etc.)?

stairs 


\section{LEFT LOWER LEG}

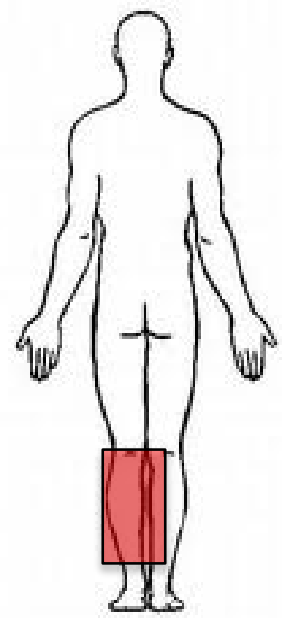

How much does lower leg pain affect your gait?

Strong limping

Never, very

rarely

How often do you have lower leg pain in physical rest?

Constantly,

always

Never, very

rarely

How intense is this lower leg in physical rest?

Extreme pain

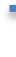

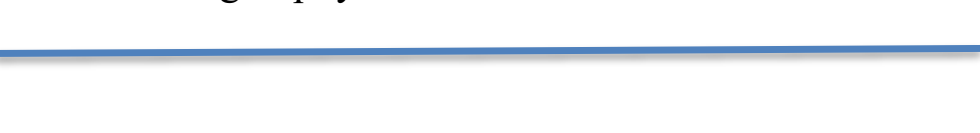

No pain

How often do you have lower leg pain during physical activity?

\begin{tabular}{|l|}
\hline $\begin{array}{l}\text { Constantly, } \\
\text { always }\end{array}$ \\
\hline
\end{tabular}

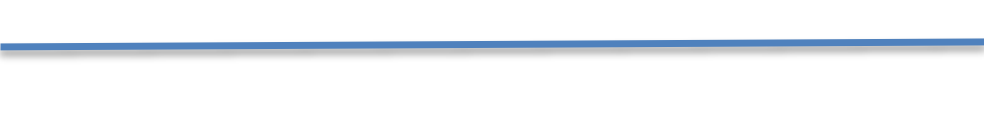

Never, very

rarely

How strong is this lower leg pain during physical activity?

Strong limping
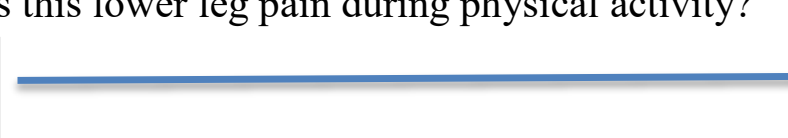

Never, very rarely

How much do lower leg problems affect your daily activities (eg. getting dressed, eating, washing, etc.)?

$$
\begin{aligned}
& \text { Impossible on } \\
& \text { my own, need } \\
& \text { constant heln }
\end{aligned}
$$

No limitation

climbing

stairs 


\section{RIGHT FOOT/ANKLE}

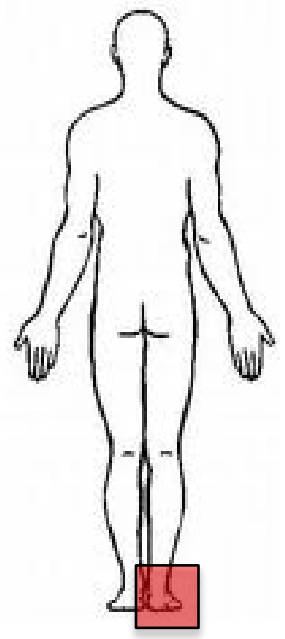

How much does foot/ankle pain affect your gait?

Strong limping

Never, very

rarely

How often do you have foot/ankle pain in physical rest?

\begin{tabular}{l}
$\begin{array}{l}\text { Constantly, } \\
\text { always }\end{array}$ \\
\hline
\end{tabular}

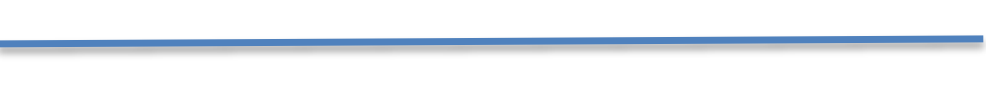

Never, very

rarely

How intense is this foot/ankle in physical rest?

Extreme pain

No pain

How often do you have foot/ankle pain during physical activity?

\section{Constantly,}

always

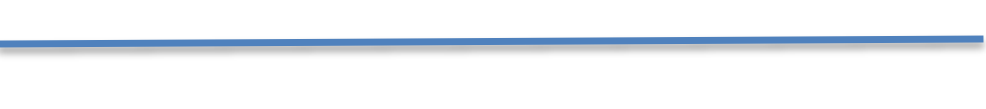

Never, very rarely

How strong is this foot/ankle pain during physical activity?

Strong limping

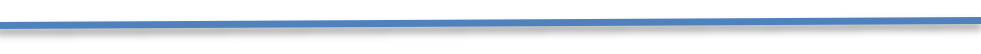

Never, very rarely

How much do foot/ankle problems affect your daily activities (eg. getting dressed, eating, washing, etc.)? 


\section{LEFT FOOT/ANKLE}

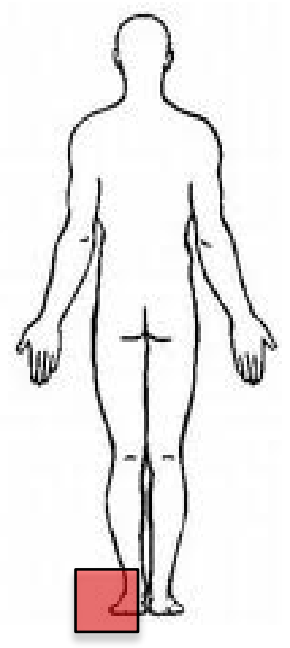

How much does foot/ankle pain affect your gait?

Strong limping

Never, very

rarely

How often do you have foot/ankle pain in physical rest?

\begin{tabular}{l}
$\begin{array}{l}\text { Constantly, } \\
\text { always }\end{array}$ \\
\hline
\end{tabular}

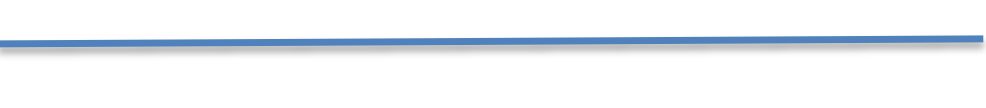

Never, very

rarely

How intense is this foot/ankle in physical rest?

Extreme pain

No pain

How often do you have foot/ankle pain during physical activity?

Constantly,

always

Never, very

rarely

How strong is this foot/ankle pain during physical activity?

Strong limping

-

Never, very rarely

How much do foot/ankle problems affect your daily activities (eg. getting dressed, eating, washing, etc.)?

Pre-Pregnancy (Please Circle Area(s) of Pain) 

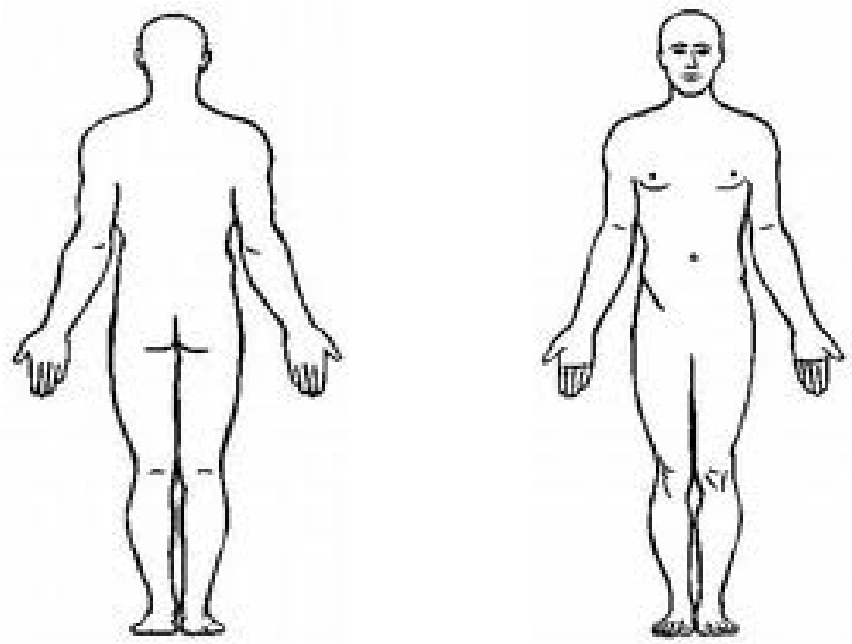

How much does this pain affect your gait?

Strong limping

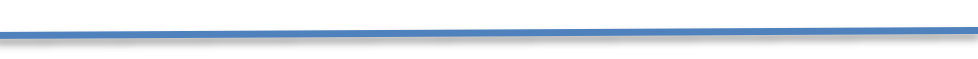

Never, very

rarely

How often do you have this pain in physical rest?

Constantly,

always

Never, very rarely

How intense is this pain in physical rest?

Extreme pain

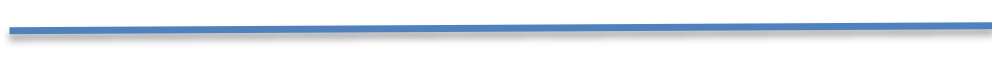

How often do you have this pain during physical activity?

Constantly,

always

Never, very

rarely

How strong is this pain during physical activity?

Strong limping

Never, very

rarely

How much do these problems affect your daily activities (eg. getting dressed, eating, washing, etc.)?

No limitation climbing

stairs 
Appendix $\mathrm{C}$

\section{Alignment Postpartum: Measurement Chart}

Subject:

Date:

Age:

Height:

Weight:

\section{Beighton's Test:}

Trunk flexion w/ palms flat:

Knees bent backward:

Elbows bent backward:

Thumbs to forearm:

Little fingers beyond $90^{\circ}$ :

(1 pt)

(2 pts)

(2 pts)

(2 pts)

(2 pts)

\begin{tabular}{|l|l|l|}
\hline & Left & Right \\
\hline ASIS $\rightarrow$ PSIS & & \\
\hline ASIS $\rightarrow$ MM & \\
\hline PSIS $\rightarrow$ MM & \\
\hline
\end{tabular}

IC Height: stand

sit

Total:

(9 pts)

Biomechanical Measurements

\begin{tabular}{|l|l|l|}
\hline & Left & Right \\
\hline Leg length & & \\
\hline Foot width $(\mathrm{cm})$ & & \\
\hline
\end{tabular}

\begin{tabular}{|l|l|l|l|l|}
\hline & Sit & Stand & Sit & Stand \\
\hline FL $(\mathrm{cm})$ & & & & \\
\hline TFL $(\mathrm{cm})$ & & & & \\
\hline FH $(\mathrm{cm})$ & & & & \\
\hline
\end{tabular}

\begin{tabular}{|l|l}
\hline Sit \& Reach $(\mathrm{cm})$ & Trial 1:
\end{tabular}

Trial 2: 
Appendix D

Subject \#__ Date:

\section{Subject Questionnaire}

1. Number of pregnancies

a. Were any miscarriages? Yes $\square$ No $\square$

2. Age(s) during pregnancy/pregnancies?

3. How long has it been since your last delivery?

4. Did you nurse? Yes $\square$ No $\square$

5. Are you currently nursing? Yes $\square$ No

6. Were you diagnosed with postpartum depression? Yes $\square$ No

7. Did you exercise prior to pregnancy? Yes $\square$ No $\square$

Describe your physical activity/exercise habits (please include frequency and duration in a normal week) Example: Walking for 30 minutes at least 3 days of the week

8. Did you exercise during pregnancy? Yes $\square$ No $\square$

Describe your physical activity/exercise habits (please include frequency and duration in a normal week) Example: Walking for 30 minutes at least 3 days of the week

9. Describe your current physical activity/exercise habits (please include frequency and duration in a normal week) Example: Walking for 30 minutes at least 3 days of the week 